\title{
Gating of Hippocampal-Evoked Activity in Prefrontal Cortical Neurons by Inputs from the Mediodorsal Thalamus and Ventral Tegmental Area
}

\author{
Stan B. Floresco and Anthony A. Grace \\ Department of Neuroscience, University of Pittsburgh, Pittsburgh, Pennsylvania 15206
}

\begin{abstract}
Projections from the hippocampus, the mediodorsal thalamus (MD), and the ventral tegmental area (VTA) form interconnected neural circuits that converge in the prefrontal cortex (PFC) to participate in the regulation of executive functions. The present study assessed the roles that the MD and VTA play in regulating the hippocampal-PFC pathway using extracellular single-unit recordings in urethaneanesthetized rats. MD stimulation inhibited PFC neuron firing ( $\sim 100 \mathrm{msec}$ duration) evoked by fimbria/fornix (FF) stimulation in a majority of neurons tested. However, this effect was reduced if activation of thalamocortical inputs occurred almost simultaneously (10 $\mathrm{msec})$ with stimulation of the FF. In a separate population of neurons, burst stimulation of the MD produced a short-term $(\sim 100 \mathrm{msec})$ inhibition or facilitation of FF-evoked firing in 66 and 33\% of PFC neurons, respectively. Moreover, tetanic stimulation of the MD caused a longer-lasting $(\sim 5 \mathrm{~min})$ potentiation of FF-evoked firing. Burst stimulation of the VTA inhibited FF-evoked firing in a frequencydependent manner: firing evoked by higher-frequency trains of pulses to the FF was less inhibited than firing evoked by single-pulse stimulation. The inhibitory actions of VTA stimulation were augmented by $\mathrm{D}_{1}$ receptor antagonism and attenuated by $\mathrm{D}_{2}$ and $\mathrm{D}_{4}$ antagonists. Moreover, stimulation of the MD $10 \mathrm{msec}$ before stimulation of the FF attenuated the VTA-mediated inhibition of evoked firing. Thus, both the MD and VTA exert a complex gating action over PFC neural activity, either facilitating or inhibiting firing in the hippocampal-PFC pathway depending on the frequency and relative timing of the arrival of afferent input.
\end{abstract}

Key words: prefrontal cortex; hippocampus; ventral tegmental area; mediodorsal thalamus; dopamine; in vivo electrophysiology; gating; rat

\section{Introduction}

Studies in both animals and humans have implicated the prefrontal cortex (PFC) and related subcortical afferent connections in mediating executive functions such as prospective coding, setshifting, and working memory (Kolb, 1984; Hauser, 1999; Robbins, 1996; Goldman-Rakic, 1998; Miller, 2000). A contemporary theory of PFC function posits that the frontal lobes play an essential role in integrating different types of information, subserved by distinct cortical and subcortical networks, to organize behavior for the attainment of future goals (Miller, 2000; Fuster, 2001). Hippocampal projections to the PFC form one transcortical network that mediates cognitive processes such as working memory. In the rat, the ventral CA1/subicular region of the hippocampus sends glutamatergic projections to both pyramidal neurons and GABAergic interneurons of the prelimbic region of the PFC (Conde et al., 1995; Carr and Sesack, 1996; Gabbott et al., 2002). Stimulation of hippocampal afferents evokes excitatory and inhibitory responses in PFC neurons (Gigg et al., 1994; Jay et al., 1995, Mulder et al., 1997; Lewis and O'Donnell, 2000). The importance of hippocampal-PFC circuits in working memory is underscored by the finding that disconnection between these re-

Received Nov. 25, 2002; revised Feb. 4, 2003; accepted Feb. 18, 2003

This work was supported by United States Public Health Service Grants MH 01055, MF 57440, and MH 45156. S.B.F. is a recipient of a Human Frontiers Science Organization Post-Doctoral Fellowship. We thank Christy Smolak and Nicole MacMurdo for their assistance with histology and Pfizer for their generous donation of CP293,019.

Correspondence should be addressed to Dr. Stan B. Floresco, Department of Neuroscience, University of Pittsburgh, 446 Crawford Hall, Pittsburgh, PA, 15260. E-mail: floresco@brain.bns.pitt.edu.

Copyright $\odot 2003$ Society for Neuroscience $\quad 0270-6474 / 03 / 233930-14 \$ 15.00 / 0$ gions selectively disrupts retrieval of information during delayed responding (Floresco et al., 1997; Aujla and Beninger, 2001).

Two other subcortical nuclei that play a role in cognitive processes mediated by the hippocampal-PFC circuits include the ventral tegmental area (VTA) and the mediodorsal nucleus of the thalamus (MD). The VTA sends a dopaminergic projection to the PFC (Van Eden et al., 1987), and dopamine (DA) terminals are found often in close proximity to hippocampal terminals on PFC neurons (Carr and Sesack, 1996). Intracellular in vivo recordings have shown that stimulation of the VTA can produce a prolonged depolarization in PFC neurons accompanied by a reduction in spike firing (Lewis and O'Donnell, 2000). Moreover, VTA activation can exert two differential effects on hippocampal-evoked activity of PFC neurons: (1) an inhibition of firing evoked by low-frequency stimulation of the ventral subiculum and (2) an enhancement of long-term potentiation of the hippocampalPFC pathway induced by high-frequency stimulation (Jay et al., 1995; Gurdren et al., 1999). These data suggest that DA input plays an important neuromodulatory role over activity in the hippocampal-PFC pathway, a contention supported by the findings that selective disruption of $\mathrm{DA} \mathrm{D}_{1}$ receptor modulation of hippocampal inputs to the PFC impairs working memory mediated by hippocampal-PFC circuits (Seamans et al., 1998; Aujla and Beninger, 2001). The functional role of $\mathrm{D}_{2}$-like $\left(\mathrm{D}_{2}, \mathrm{D}_{4}\right)$ receptors in the PFC remains to be established; however, activation of these receptors tends to inhibit PFC neural activity, either by direct actions on PFC pyramidal neurons or by facilitating 
GABAergic transmission (Sesack and Bunney, 1989; Rubinstein et al., 2001; Wedzony et al., 2001).

The MD shares a reciprocal glutamatergic projection with the PFC with thalamocortical inputs synapsing on layer III and V neurons, and possibly GABAergic interneurons as well (Krettek and Price, 1977; Groenewegen, 1988; Ray and Price, 1992; Pirot et al., 1994; Kuroda et al., 1998). Behavioral studies have implicated the $\mathrm{MD}$ in a broad range of PFC-related processes, including prospective coding (Joyce and Robbins, 1991; Daum and Ackermann, 1994) and strategy selection (Hunt and Aggleton, 1998). Of particular relevance is the fact that disconnection between the $\mathrm{MD}$ and PFC disrupts working memory processes dependent on both hippocampal-PFC circuits and mesocortical DA (Floresco et al., 1999).

The above-mentioned findings suggest that converging corticopetal inputs originating from the hippocampus, the MD, and the VTA may interact in a cooperative manner to regulate executive functions governed by the PFC. Despite this, it is surprising that there is a paucity of research investigating the mechanisms by which these inputs interact to influence PFC neural activity. As such, the present study was undertaken to assess the modulatory actions that inputs from the MD and the VTA exert over hippocampal-evoked firing of PFC neurons, using in vivo extracellular single-unit recordings.

\section{Materials and Methods}

\section{Subjects and surgery}

Male Sprague Dawley rats (300-400 gm; Hilltop, Scottsdale, PA) were anesthetized with urethane ( $1.5 \mathrm{gm} / \mathrm{kg}$, i.p.) and mounted in a stereotaxic frame, with the incisor bar set at $-3.3 \mathrm{~mm}$. Body temperature was maintained at $37^{\circ} \mathrm{C}$ with a temperature-controlled heating pad. In all surgical preparations, the scalp was incised and holes were drilled in the skull overlying the prelimbic region of the medial PFC, the fornix/fimbria (FF), the MD, and the VTA. Concentric bipolar electrical stimulating electrodes (SNE-100; Kopf, Tujunga, CA) were implanted into the three afferent regions of the PFC. The stereotaxic coordinates were as follows (flat skull): $\mathrm{FF}$ electrode $=$ anteroposterior $(\mathrm{AP})-1.3 \mathrm{~mm}$ (bregma), mediolateral $(\mathrm{ML})+1.6 \mathrm{~mm}$, dorsoventral (DV) $-4.0 \mathrm{~mm}$ (cortex); $\mathrm{MD}$ electrode $=\mathrm{AP}-2.9 \mathrm{~mm}$, ML $+0.7 \mathrm{~mm}$, DV $-5.3 \mathrm{~mm}$; VTA electrode $=\mathrm{AP}-5.4 \mathrm{~mm}, \mathrm{ML}+0.7 \mathrm{~mm}, \mathrm{DV}-7.8 \mathrm{~mm}$. Animal care and surgical procedures were performed in accordance with the guidelines outlined in the NIH Guide for the Care and Use of Laboratory Animals and were approved by the Institutional Animal Care and Use Committee of the University of Pittsburgh.

\section{Extracellular recordings and cell-searching procedures}

Extracellular recording microelectrodes were constructed from $2.0 \mathrm{~mm}$ outer diameter borosilicate glass capillary tubing (WPI) using a vertical micropipette puller (Narishige, Tokyo, Japan). The tips of the electrodes were broken back against a glass rod to $\sim 1 \mu \mathrm{m}$ tip diameter and filled with $2 \mathrm{M} \mathrm{NaCl}$ containing $2 \%$ Pontamine sky blue dye. The in vitro impedance of the microelectrodes ranged from 5 to $10 \mathrm{M} \Omega$ as measured at $135 \mathrm{~Hz}$ using a Winston Electronics BL-1000 impedance meter. After a burr hole was drilled overlying the PFC, the dura was resected, and the electrode was lowered into the PFC (coordinates: $+3.5-2.7 \mathrm{~mm}$ anterior from bregma, $0.6-0.8 \mathrm{~mm}$ lateral from the midline, $2.2-5.0 \mathrm{~mm}$ ventral from brain surface) with a hydraulic microdrive (Kopf Model 640). The electrode signal was amplified, filtered $(400-4000 \mathrm{~Hz})$, and discriminated from noise using a combination amplification and window discrimination unit for extracellular recording (Fintronics, Orange, CT) and displayed on an oscilloscope (Tektronics, Wilsonville, OR). The data were acquired, stored, and analyzed using custom-designed computer software (Neuroscope) running on an Intel-based personal computer with a data acquisition board interface (Microstar Laboratories, Bellevue, WA).

After the glass microelectrodes had been lowered to the dorsal border of the PFC, a cell-searching procedure began. In this procedure, the microelectrode was lowered incrementally through the PFC while alternating stimuli were delivered to the FF and the MD $(1500 \mu \mathrm{A})$ at $1 \mathrm{sec}$ intervals (i.e., each afferent was stimulated at $0.5 \mathrm{~Hz}$ ). Although previous in vitro studies in hippocampus neurons have shown that prolonged low-frequency stimulation can induce long-term depression (Mulkey and Malenka, 1992), other studies in vivo have shown that extended bouts of low-frequency stimulation $(1 \mathrm{~Hz}, 15 \mathrm{~min}$ ) of the hippocampus does not produce any reliable change in synaptic efficacy in the PFC (Burette et al., 1997). Cathodal constant current pulses (0.2 msec duration) were delivered to the FF and MD through an Iso-Flex optical isolator (A.M.P.I., Jerusalem, Israel) via a Master-8 programmable pulse generator (A.M.P.I.) using the parameters noted below. Once a cell was detected, the position of the microelectrode was adjusted to maximize the spike amplitude relative to background noise. Neurons that responded only to FF stimulation or MD stimulation or received converging input from both regions were identified by their robust excitatory response after stimulation of the respective afferent region. Only neurons that responded with an orthodromic, monosynaptic response and displayed a signal-to-noise ratio of at least 3:1 were used in the data analysis. Evoked firing was characterized as monosynaptic/orthodromic if the response displayed spike jitter of at least $2 \mathrm{msec}$ and a shift in spike latency with increasing current amplitude, followed by paired-pulse stimulation at $50 \mathrm{~Hz}$ (otherwise characterized as polysynaptic), but failed to follow $400 \mathrm{~Hz}$ paired-pulse stimulation (otherwise characterized at antidromic) (Pirot et al., 1994; Mulder et al., 1997).

With respect to MD-evoked responses, previous studies have demonstrated that electrical stimulation of the MD can evoke two types of monosynaptic responses in PFC neurons. Single-pulse stimulation can evoke a short latency $(<10 \mathrm{msec})$ action potential that likely represents orthodromic activation of thalamocortical axons. However, higherfrequency $(10 \mathrm{~Hz})$ stimulation yields longer latency $(>13 \mathrm{msec})$ spikes that are thought to be caused by antidromic activation of axons of PFC projection neurons that terminate in the MD but also have collaterals that synapse onto other PFC neurons (Pirot et al., 1994). Experiments assessing the conduction velocities of MD neurons projecting to the PFC have revealed that antidromically evoked firing of MD neurons occurs 2-11 msec after PFC stimulation (Pirot et al., 1994). In the present study, we observed that orthodromic monosynaptic action potentials evoked by single-pulse stimulation of the MD displayed a latency range of 6-22 msec $($ mean $=13.4 \mathrm{msec})$. However, to maximize the possibility that these responses were driven by activation of thalamocortical projections and not axon collaterals of PFC projection neurons, we included only $\mathrm{PFC}$ neurons that displayed MD-evoked orthodromic firing with latencies of $\leq 12$ msec. Whenever a PFC neuron was encountered that displayed an antidromic spike after MD stimulation (but no response to FF stimulation), the location of that neuron was noted, but no other data were taken.

\section{Stimulation protocols}

After establishing that firing evoked by stimulation of the FF or MD was monosyaptic and orthodromic, stimulation currents were adjusted to submaximal stimulation intensity (range $100-1800 \mu \mathrm{A}$ ) so that stimulation of the FF or MD would evoke an action potential $\sim 60 \%$ of the time (range $40-75 \%$, depending on the experiment) in response to singlepulse stimulation delivered at $0.2 \mathrm{~Hz}$. In each of these experiments, data were compiled using a minimum of 25 sweeps. We used various stimulation protocols designed to investigate different types of interactions among hippocampal, MD, and VTA inputs to the PFC.

Interactions between converging inputs from the hippocampal and $M D$ in the PFC: sequential-pulse protocols. In PFC neurons that displayed a monosynaptic orthodromic spike after stimulation of both the FF and $\mathrm{MD}$, we conducted a series of sequential single-pulse stimulation experiments to assess how stimulation of one input could influence firing evoked by stimulation of the second input. In these experiments, each neuron received a conditioning pulse of one input followed by a test pulse of the other input, at intervals ranging between 10 and $500 \mathrm{msec}$, in a counterbalanced order, using the same stimulation intensity for each interstimulus interval (ISI). Paired-pulse facilitation/depression was also 
examined for each individual input, using 25-100 msec intervals between the conditioning pulse and the test pulse.

Modulation of hippocampal-evoked firing by burst stimulation of the $M D$. For some PFC neurons that only fired in response to FF and not MD stimulation, a series of experiments assessed the effect of burst stimulation of the MD on firing evoked by FF stimulation. In these studies, the stimulation intensity of the FF was adjusted so that the firing probability was $\sim 50 \%$ and kept constant throughout the course of the experiment. The firing probability was maintained at $\sim 50 \%$ so that we would be able to observe either inhibition or facilitation of FF-evoked firing by MD burst stimulation. After establishing baseline firing probabilities, we applied a four-pulse, $20 \mathrm{~Hz}$ train to the $\mathrm{MD}(800-1000 \mu \mathrm{A}) 10$, 25, or 50 msec before the FF pulse, with 25 sweeps collected for each interstimulus interval. This firing pattern mimics that displayed by MD neurons during learning (Oyoshi et al., 1996). Any neuron that displayed reliable firing in response to MD burst stimulation was not included in the data analysis. After each series of 25 sweeps, FF-evoked firing probability was monitored at the same stimulation intensity for 3-5 min using single pulses to the FF delivered at $0.2 \mathrm{~Hz}$. This continued until the FF-evoked firing probability returned to $\sim 50 \%$.

We also assessed effects of tetanic stimulation of the MD on longer lasting (i.e., minutes) changes of FF-evoked firing in PFC neurons. In this experiment, baseline probability of evoked firing in response to single pulses delivered to the FF were recorded over $\sim 10 \mathrm{~min}$, using repeated sweeps administered every $2.5 \mathrm{~min}$. Once stable levels of evoked-firing activity were observed ( $\leq 15 \%$ variation in spike probability over $5-10$ $\mathrm{min}$, three to four sweeps), 25 trains (four pulses, $20 \mathrm{~Hz}$ ISI) were delivered to the MD at a frequency of $0.2 \mathrm{~Hz}$. Thirty seconds after this tetanus (assigned as time 0 ), the $\mathrm{FF}$ was again stimulated with single pulses at 0.2 $\mathrm{Hz}$ using the same stimulation current as before tetanus, and changes in FF-evoked firing probability were assessed for another $10 \mathrm{~min}$ with repeated sweeps recorded every $2.5 \mathrm{~min}$. Data were normalized to the average firing probability observed over $5 \mathrm{~min}$ before tetanus and analyzed in terms of percentage change in firing probability. For both of the above-mentioned protocols, any neuron displaying reliable firing in response to MD burst stimulation was not included in the data analysis.

VTA modulation of FF-evoked firing of PFC neurons. For these experiments, FF stimulation intensities were adjusted to evoke an action potential $\sim 60-75 \%$ of the time after single-pulse stimulation of the FF delivered at $0.2 \mathrm{~Hz}$. Once baseline firing probabilities were established, the VTA was stimulated in a burst pattern (two four-pulse $20 \mathrm{~Hz}$ trains of pulses; interburst interval $=200 \mathrm{msec}$ ) 10 or $50 \mathrm{msec}$ before stimulation of the FF. Usually we stimulated the VTA with an intensity of $600 \mu \mathrm{A}$, but in some instances, the intensity was increased to up to $800 \mu \mathrm{A}$ to induce a noticeable inhibition of FF-evoked firing. To assess whether activation of the VTA exerted a frequency-dependent modulation of evoked firing, we stimulated the FF first with single pulses and then with five-pulse, 20 $\mathrm{Hz}$ trains, each delivered at $0.2 \mathrm{~Hz}$. The $20 \mathrm{~Hz}$ stimulation frequency mimics the way hippocampal projection neurons fire during working memory tasks (Hampson et al., 2000). We used a minimum of 25 sweeps per interburst interval to compile the data for all experiments assessing the effects of VTA stimulation.

\section{Pharmacological manipulations}

For some experiments involving burst stimulation of the VTA, separate groups of rats were implanted with intravenous jugular catheters, consisting of $\mathrm{PE} 10$ tubing attached to a 30 ga needle and a $1 \mathrm{ml}$ syringe. These experiments used a between-subjects design, and every animal received only one drug injection. After isolation of each PFC neuron, we confirmed that burst stimulation of the VTA inhibited hippocampal-evoked firing induced by single-pulse stimulation of the FF before drug administration. Baseline levels of FF-evoked firing were established, after which drugs were administered. We would then wait 10-20 min after drug injection before stimulating the VTA again. All drugs were purchased from Sigma (St. Louis, MO), with the exception of CP 293,019, which was donated by Pfizer (Groton, $\mathrm{CT}$ ). The selective $\mathrm{D}_{1}$ receptor antagonist $\mathrm{SCH} 23390(0.2 \mathrm{mg} / \mathrm{kg})$, the selective $\mathrm{D}_{2}$ antagonist eticlopride $(0.25 \mathrm{mg} /$ $\mathrm{kg}$ ), and the selective NMDA receptor antagonist 3-(2-carboxypiperazin4-yl)-propyl-1-phosphonic acid (CPP) $(2.0 \mathrm{mg} / \mathrm{kg})$ were dissolved in physiological saline. The $\mathrm{D}_{2} / \mathrm{D}_{4}$ antagonist haloperidol $(0.5 \mathrm{mg} / \mathrm{kg})$ was dissolved in dilute lactic acid. The selective $\mathrm{D}_{4}$ antagonist CP 293,019 (10 $\mathrm{mg} / \mathrm{kg}$ ) was immersed in a drop of $\mathrm{NaOH}$ and $40 \%$ solution of cyclodextrin and sonicated until dissolved. The concentrations of these solutions were set so that injection volumes would range between 0.15 and $0.30 \mathrm{ml}$, and no more than one drug injection was given per animal. The doses of these drugs were chosen from previous studies (Gioanni et al., 1998; Mansbach et al., 1998; Floresco et al., 2001).

\section{Histology}

At the end of each experiment, the recording site in the PFC was marked via iontophoretic ejection of Pontamine sky blue dye from the tip of the recording electrode ( $30 \mu \mathrm{A}$ constant current for 20-30 min). Iron deposits were made in the fimbria, the $\mathrm{MD}$, and the VTA stimulation sites by passing DC current ( $100 \mu \mathrm{A}$ for $10 \mathrm{sec}$ ) through the stimulating electrode. After dye ejection, brains were removed and fixed in formalin containing $0.1 \%$ potassium ferricyanide for at least $24 \mathrm{hr}$. The brains were then immersed in phosphate-buffered sucrose solution (25\%) until saturated. The tissue was sectioned into $40 \mu \mathrm{m}$ coronal slices, mounted, and stained with cresyl violet to enable histological determination of recording and stimulating electrode sites. Representative locations of different classes of PFC neurons and stimulating electrodes are presented in Figure 1.

\section{Data analysis}

The data were analyzed in terms of evoked firing probability in response to stimulation of the FF or MD, or percentage change of baseline-evoked firing probability. Evoked firing probabilities were calculated by dividing the number of action potentials observed by the number of stimuli administered (typically $25-50$ pulses) $\times 100$. For the sequential-pulse experiments that measured the interactions between hippocampal and MD inputs, the baseline firing probabilities evoked by each input were calculated by taking the mean firing probability evoked when that input was stimulated as the conditioning pulse. Changes in these probabilities were used as an index of the influence that MD or VTA inputs exerted over hippocampal-evoked firing of PFC neurons. The type of statistical analysis depended on the particular experiment, but typically entailed two- or three-way repeated measures ANOVA, with the exception of the pharmacological studies, which also included drug as a between-subjects factor. Multiple comparisons were made using two-tailed Dunnett's test for repeated measures.

\section{Results}

\section{General properties of PFC $\leftarrow$ Hipp neurons: convergence of inputs and projections to the MD and VTA}

The data from a total of 114 PFC neurons that displayed a monosynaptic orthodromic spike after stimulation of the FF are presented here (hereafter referred to as PFC $\leftarrow$ Hipp neurons). These cells displayed a mean basal spontaneous firing rate of $3.1 \pm 0.5$ $\mathrm{Hz}$ (range $0.0-17.2 \mathrm{~Hz}$; median firing rate $2.9 \mathrm{~Hz}$ ) and had a mean evoked firing latency of $11 \pm 0.8 \mathrm{msec}$ (range 7-17 msec), consistent with previous findings (Mulder et al., 1997). Most of these 114 neurons that fired in response to FF stimulation were also tested for an antidromic response to MD or VTA stimulation. Ten of these cells (10 of 109; 9.2\%) were confirmed $\mathrm{PFC} \rightarrow \mathrm{MD}$ projection neurons (mean antidromic spike latency $=11.2 \pm 0.9 \mathrm{msec}$; range $7-18 \mathrm{msec}$ ), whereas $24.6 \%$ of these neurons (17 of 69) responded with an antidromic spike after VTA stimulation (mean antidromic spike latency $=9.6 \pm$ $1.0 \mathrm{msec}$; range $4-19 \mathrm{msec})$. In addition, 4 of 60 neurons $(6.7 \%)$ responded with an antidromic spike after stimulation of both the VTA and MD, suggesting that a subpopulation of PFC neurons that receive hippocampal input send axon collaterals to both regions (Fig. 1E). It is notable that many of the PFC $\leftarrow$ Hipp neurons were located in the same vertical electrode track where other PFC neurons that were antidromically activated by MD stimulation were observed. This suggests that most of the PFC $\leftarrow$ Hipp 

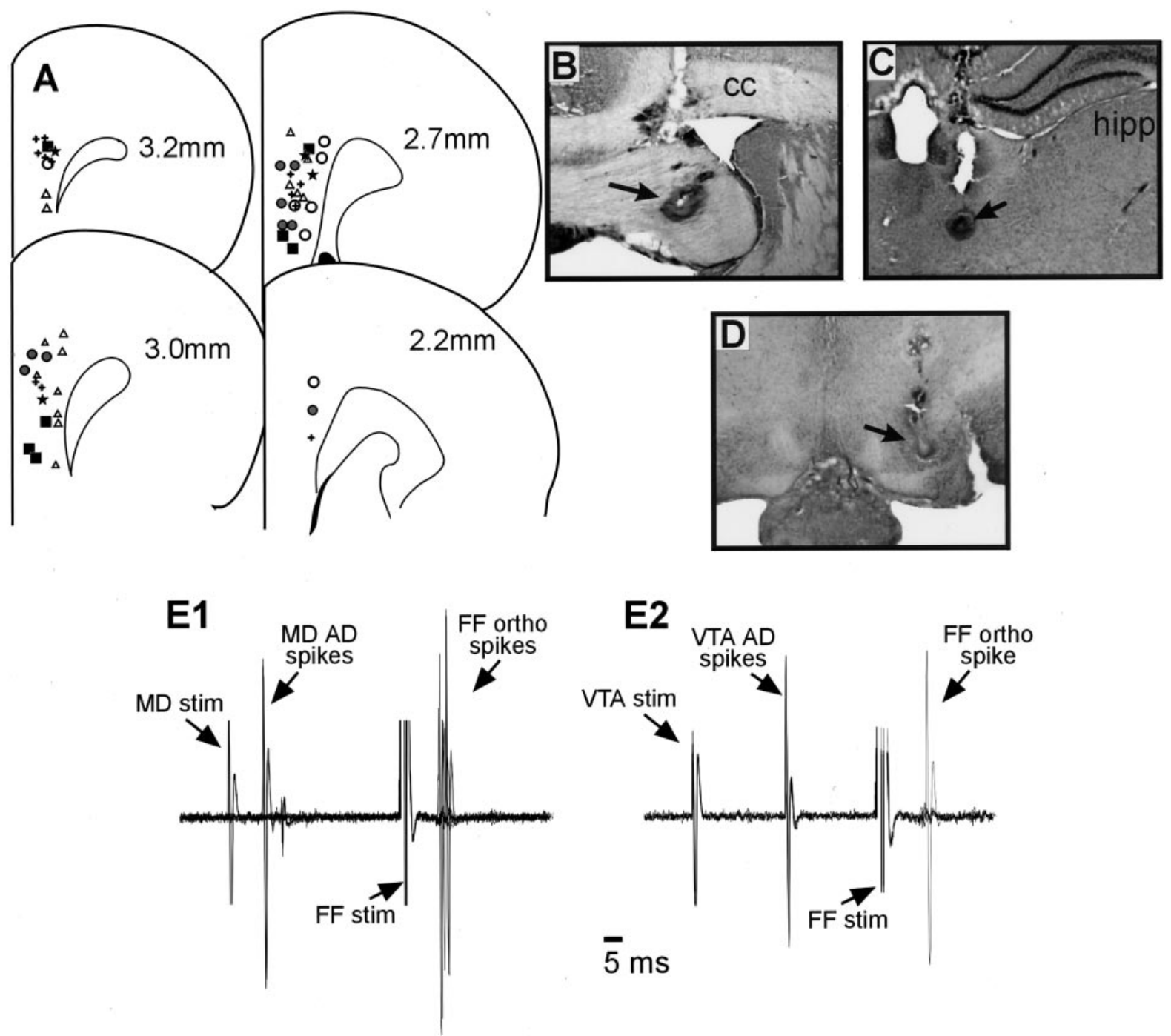

Figure 1. Histology. A, Schematic of coronal sections of the rat brain showing representative placements of recording electrodes where different PFC neurons were observed. PFC $\longleftarrow$ Hipp neurons, black square; neurons that responded with an orthodromic action potential after MD stimulation, gray circles; PFC $\leftarrow$ Hipp cells that were confirmed to project to the MD, open circles; PFC $\leftarrow$ Hipp cells that were confirmed to project to the VTA; PFC $\longleftarrow$ Hipp cells that were antidromically activated by both the VTA and the MD, stars; PFC $\rightarrow$ MD projection neurons that did not respond to FF stimulation, triangles. Numbers correspond to millimeters from bregma. $B-D$, Photographs of a representative placement of a stimulating electrode in the FF $(B)$, the $M D(C)$, and the VTA $(D)$. Arrows highlight the location of stimulating electrode placements. cc, Corpus callosum; hipp, hippocampus. E, Individual data. Ten overlaid traces recorded from a PFC neuron that displayed an antidromic (AD) spike after MD stimulation and an orthodromic (ortho) spike after FF stimulation (E1). This same neuron could also be activated antidromically by stimulation of the VTA (E2) (5 traces).

neurons that were recorded in the present study were located in the projection layers of the PFC. Last, and most pertinent to the present study, 13 of 105 PFC $\leftarrow$ Hipp neurons $(12.4 \%)$ also displayed converging orthodromic input from the MD, exhibiting a monosynaptic action potential after MD stimulation that was within the latency range of our inclusion criterion (mean spike latency $=7.6 \pm 0.6 \mathrm{msec}$ ). Representative locations of these neurons are shown in Figure 1. PFC $\leftarrow$ Hipp neurons that projected to the MD were clustered in the more rostral regions of the $\mathrm{PFC}$ and found in both prelimbic and infralimbic areas, whereas PFC $\leftarrow$ Hipp neurons that projected to the VTA clustered more rostrally and were located in the dorsal prelimbic region.

\section{Interactions between converging hippocampal and $\mathrm{MD}$ inputs to the PFC}

In six PFC neurons that displayed a monosynaptic spike in response to stimulation of both the FF and the MD (six rats), we administered a sequential-pulse stimulation protocol to assess how stimulation of one input could influence firing driven by the other input. In these cells, the basal firing probabilities evoked by either FF or MD single-pulse stimulation did not differ $(\mathrm{FF}=$ $\left.55.7 \pm 4 / 7 \% ; \mathrm{MD}=53.6 \pm 7.3 \% ; F_{(1,5)}=0.04 ; \mathrm{NS}\right)$. Application of a conditioning pulse to the FF $10-500$ msec before a test pulse to the MD resulted in a profound and significant $(p<0.05)$ depression of MD evoked firing probability (Fig. $2 A$, black squares) compared with single-pulse stimulation of the MD alone (Fig. $2 A$, gray square) $\left(F_{(6,30)}=3.5, p<0.01\right.$; and Dunnett's, $p<0.05)$. The suppression of MD-evoked firing probability was maximal when the conditioning pulse to the FF was administered 10 msec before MD stimulation ( $-94 \pm 3 \%$ ), whereas longer intervals $(25-500 \mathrm{msec})$ produced suppression of firing to between 45 and 75\% of the baseline MD-evoked firing probability. In these same neurons, a similar profile was observed when a conditioning pulse was applied to the MD before a test pulse to the FF. In this instance, FF-evoked firing probability was significantly reduced by $\sim 60 \%$ when a conditioning pulse was administered 25-100 msec before FF stimulation (Fig. 2 B, black circles) when compared with single pulse of the FF alone (Fig. $2 B$, gray 
circle). However, application of a conditioning pulse to the MD either 10 or $250-$ $500 \mathrm{msec}$ before FF stimulation did not significantly effect the FF evoked firing probability (Fig. $2 B$, white circles) $\left(F_{(6,30)}\right.$ $=5.6$; $p<0.01)$. The duration of the inhibition of MD-evoked spiking by the FF was substantially longer $(\sim 500 \mathrm{msec})$ than the reduction in FF-evoked firing mediated by the $\mathrm{MD}(\sim 100 \mathrm{msec})$. This difference may have been caused by differences in the duration of feed-forward inhibition evoked by each afferent. To investigate this difference further, we analyzed the duration of inhibition of spontaneous activity evoked by single-pulse stimulation of each afferent. In accordance with our findings using sequential-pulse protocols, single-pulse stimulation of the MD evoked an initial monosynaptic spike, which was followed by a period of inhibition of spontaneous firing that lasted $160 \pm 21 \mathrm{msec}$. In contrast, inhibition of spontaneous firing evoked by FF stimulation had a substantially longer duration ( $403 \pm 27 \mathrm{msec})$.

Subsequent analyses of these data were conducted to assess whether the neuron fired an action potential to the conditioning pulse to either MD or FF stimulation had any effect on the firing probability observed in response to the test pulse to the FF or the MD. Analysis of these data revealed that FF stimulation caused the same level of depression of MD-evoked spike firing independent of whether the FF conditioning pulse evoked a spike $\left(F_{(1,5)}=0.2 ; \mathrm{NS}\right)$. The reverse was also true: $\mathrm{MD}$ stimulation caused a similar depression in the response to FF stimulation independent of whether the MD condition pulse evoked an action potential $\left(F_{(1,5)}=2.7 ; \mathrm{NS}\right)$. Thus, activity in the hippocampal-PFC pathway $10-500 \mathrm{msec}$ before impulse activity in the MD-PFC pathway can profoundly reduce the probability of firing induced by thalamocortical inputs, an effect that is not related to FF-evoked firing. The MD-PFC pathway exerts a similar gating action over hippocampal-evoked firing, although this inhibitory action occurs at a more temporally discrete range (25-100 $\mathrm{msec})$. Importantly, the inhibitory influence that this thalamocortical pathway exerts over hippocampal-evoked firing of PFC neurons can be offset if impulse activity from the hippocampus arrives almost simultaneously with inputs from the MD (i.e., within $\sim 10 \mathrm{msec}$ ).

We also assessed paired-pulse facilitation/depression in the hippocampal-PFC or MD-PFC pathway individually, using 25, 50 , and $100 \mathrm{msec}$ interstimulus intervals between conditioning and test pulses (Table 1$)$. For PFC $\leftarrow$ Hipp neurons $(n=10$; six rats), delivering paired pulses to the FF at intervals of 50 or 100 $\mathrm{msec}$, but not at $25 \mathrm{msec}$, resulted in significant paired-pulse facilitation $(p<0.01)$. In contrast, for neurons $\mathrm{PFC} \leftarrow \mathrm{MD}(n=$ 9; five rats), there was a significant $(p<0.05)$ paired-pulse depression of the test pulse at a $100 \mathrm{msec}$ interval, but not at the 25 or $50 \mathrm{msec}$ intervals (Fig. $2 B)\left(F_{(2,34)}=6.9 ; p<0.01\right)$.

\section{Burst activation of the MD produces differential short-term gating of hippocampal-evoked firing in subpopulations of PFC neurons that are not activated by MD stimulation} In light of the dense thalamocortical projection to the PFC, we were surprised to observe that a relatively small proportion $(<15 \%)$ of PFC $\leftarrow$ Hipp neurons fired a monosynaptic action potential after stimulation of the MD. However, this may be an underestimation of the total number of PFC $\leftarrow$ Hipp neurons that may be modulated by activity in the MD-PFC pathway. For example, it is possible that a greater proportion of $\mathrm{PFC} \leftarrow$ Hipp neurons also received direct or indirect excitatory input from the $\mathrm{MD}$, but the strength of these inputs was only sufficient to evoke a subthreshold EPSP unobservable using extracellular recordings. Alternatively, a proportion of MD axons may make connections with GABAergic interneurons in the PFC, which in turn synapse on PFC $\leftarrow$ Hipp neurons. With this in mind, we assessed how activation of the MD would affect hippocampal-evoked firing in PFC neurons that only displayed an extracellular spike after FF stimulation but not after MD stimulation.

Eighteen PFC $\leftarrow$ Hipp neurons that showed no reliable excitatory or inhibitory response to single-pulse MD stimulation were tested in this manner. In these cells, single-pulse stimulation of the MD 10-50 msec before a single pulse to the FF had no discernable effect over FF-evoked firing (Fig. 3C1). We then applied repeated four-pulse, $20 \mathrm{~Hz}$ train to the MD 10-50 msec before single-pulse stimulation of the FF. In all PFC neurons that were tested in this manner $(n=18$; eight rats), burst stimulation of the $\mathrm{MD}$ had some effect over FF-evoked firing, revealing two distinct populations of PFC neurons. In 12 of these cells (67\%), burst stimulation of the MD caused a pronounced reduction in the firing probability evoked by FF stimulation at all intervals tested, when compared with the firing probability observed after singlepulse stimulation of the FF alone $\left(F_{(2,22)}=3.7, p<0.05\right.$; and Dunnett's, $p<0.01$ ) (Fig. $3 A, C 2$ ). Four of these cells were tested further using intervals of 100 and $250 \mathrm{msec}$ between the MD train and the single pulse to the FF. This protocol revealed that the inhibitory effects of MD stimulation were still apparent at intervals of $250 \mathrm{msec}$ after an MD burst (data not shown). In contrast to the above-mention effects, in another six PFC $\leftarrow$ Hipp neurons (33\%), burst stimulation of the MD had the opposite effect: an increased FF-evoked firing probability $\left(F_{(1,5)}=6.92 ; p<0.05\right)$ (Fig. 3B). The location of these two types of PFC neurons is shown in Figure 3D. We observed no consistent pattern of local- 
Table 1. Homosynaptic paired-pulse facilitation/depression in the hippocampal-PFC and MD-PFC pathways

\begin{tabular}{lllll}
\hline & \multicolumn{2}{l}{ Mean (SEM) FF-evoked firing probabilities } & & Mean (SEM) MD-evoked firing probabilities \\
\cline { 2 - 3 } ISI & Conditioning pulse & Test pulse & Conditioning pulse \\
\hline $25 \mathrm{msec}$ & $46.4(3.4)$ & $53(10.7)$ & $48(6.1)$ & Test pulse \\
$50 \mathrm{msec}$ & $40.6(5.8)$ & $60(6.3)^{*}$ & $50(6.1)$ & $44.4(8.8)$ \\
$100 \mathrm{msec}$ & $44.6(6.1)$ & $67(10.5)^{*}$ & $55.1(5.3)$ & $42.2(9.3)$ \\
\hline
\end{tabular}

*Significant differences between conditioning and test pulse firing probability at $p<0.05$.
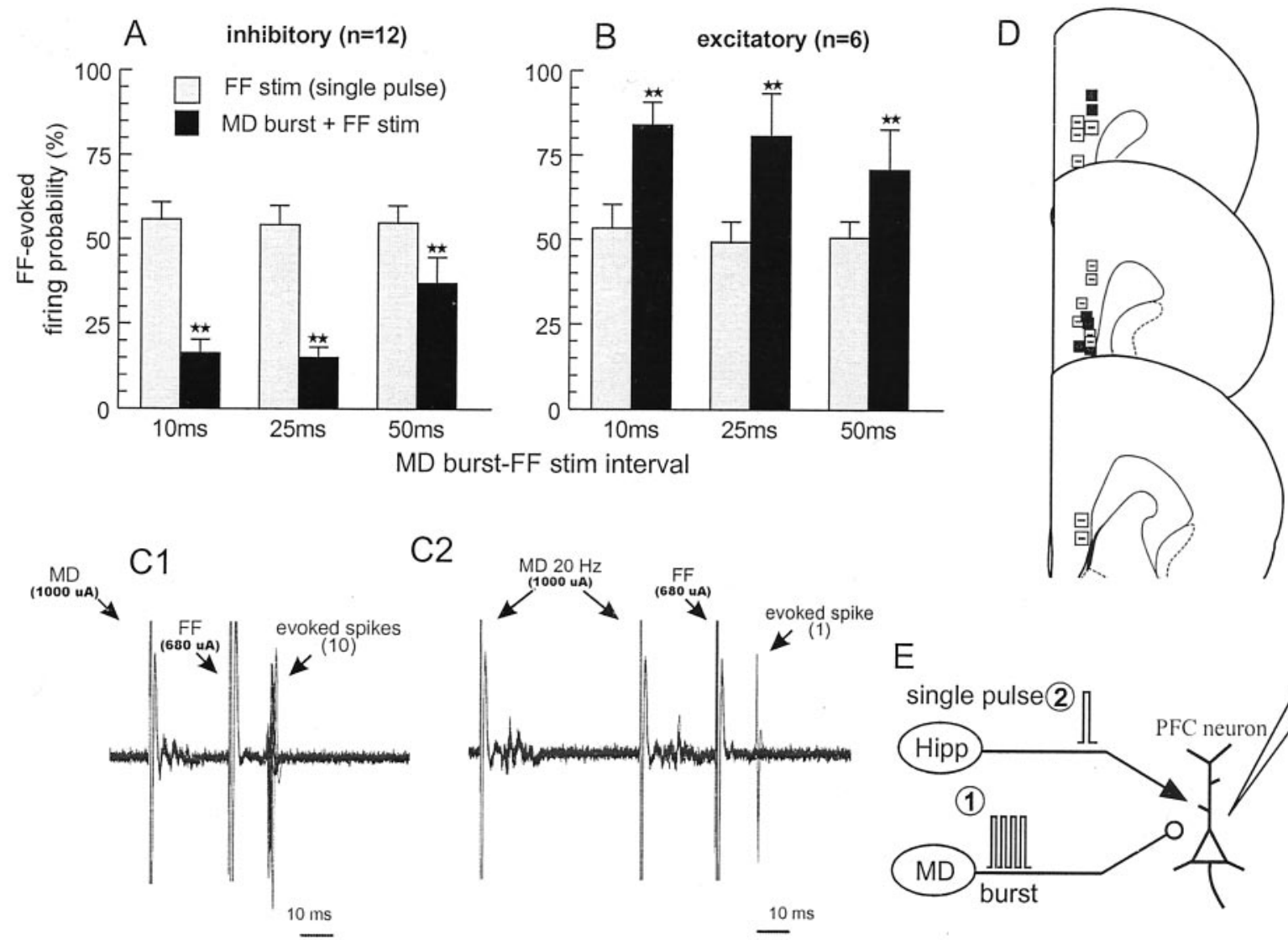

C2
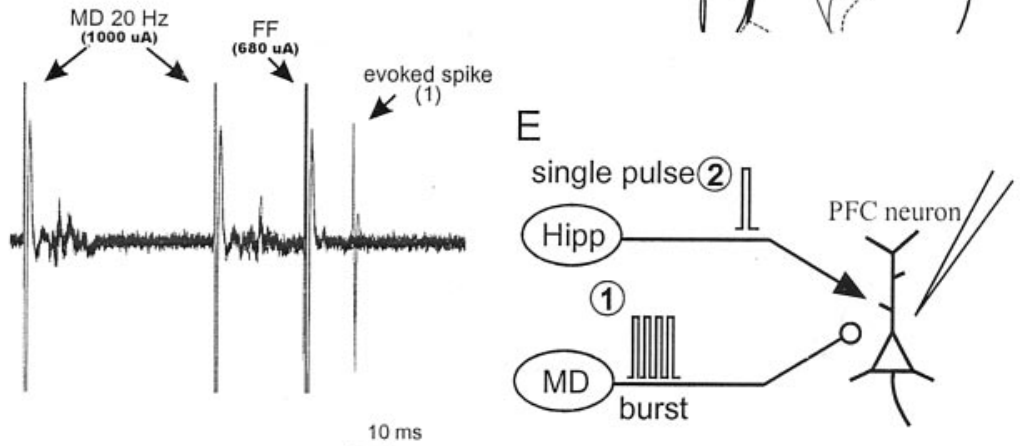

Figure 3. Burst stimulation of the MD modulates hippocampal-evoked firing in PFC neurons. $A, \ln 12$ of $18 \mathrm{PFC} \leftarrow$ Hipp neurons that did not fire in response to $\mathrm{MD}$ stimulation, burst stimulation of the MD inhibited FF-evoked firing (black bars; mean + SEM), relative to the firing probability observed after single-pulse stimulation of the FF alone at the same stimulation intensity (gray bars; mean + SEM). B, In another 6 of 18 PFC « Hipp neurons, burst stimulation of the MD facilitated FF-evoked firing. C, Representative data from individual neurons. C1, Ten overlaid traces showing the effect of single-pulse stimulation of the MD (100 $\mu \mathrm{A}) 25$ msec before stimulation of the FF $(680 \mu \mathrm{A})$. C2, In the same neuron, 10 traces showing the effect of burst stimulation of the MD (last 2 pulses shown) before FF stimulation. Over 10 sweeps, single-pulse stimulation of the MD had no effect over FF-evoked firing, but burst stimulation substantially reduced the probability of firing over the same number of trails. D, Location of PFC «Hipp neurons the evoked firing of which was inhibited (open squares and minus sign) and facilitated (black squares) by burst stimulation of the MD. $E$, Diagrams of the stimulation protocol used in this experiment. Here, the MD was stimulated with a four-pulse, $20 \mathrm{~Hz}$ train (1) $10-50$ msec before single-pulse stimulation of the FF (2). MD știmulation did not evoke firing in any of these neurons. Significant difference yersus single-pulse stimulation of the FF: ${ }^{* *} p<0.01$. ization of these two types of neurons within the PFC; both types were found in the dorsal and ventral regions of the deep layers of the prelimbic and infralimbic cortex. Thus, these data imply that natural-type bursting activity in the thalamocortical pathway can exert differential gating actions on PFC neural activity driven by hippocampal inputs. Most PFC neurons are inhibited by bursting activity in the thalamocortical pathway, whereas another group of neurons displays a facilitation of hippocampal-evoked firing after MD burst stimulation.

Repeated burst stimulation of the MD produces a longer lasting potentiation of hippocampal-evoked firing in PFC neurons

Over the course of the above-mentioned series of experiments, we noticed an increase in the FF-evoked firing probability after repetitive burst stimulation of the MD (i.e., 25 bursts delivered at

$0.2 \mathrm{~Hz}$ frequency), regardless of whether MD activation inhibited or facilitated FF-evoked firing, an effect that lasted a number of minutes. Therefore, we conducted another experiment to formally assess this heterosynaptic potentiation of FF-evoked firing by burst stimulation of the MD. Repeated burst stimulation of the $\mathrm{MD}$ resulted in a robust potentiation of FF-evoked firing probability in all neurons tested ( $n=8$; four rats) (Fig. $4 A, B 1, B 2)$. This potentiation of hippocampal evoked firing probability reached a peak at $1 \mathrm{~min}$ after tetanus $(+46.7 \pm 14 \%$ ) (Fig. 3B1,B2) and remained significantly elevated for another 6-8 min before returning to baseline levels of evoked firing probability $\left(F_{(7,91)}=\right.$ $4.7, p<0.01$; and Dunnett's, $p<0.05,0.01)$. To confirm that the potentiation of hippocampal-evoked firing was not merely caused by repetitive single-pulse stimulation of the FF, a separate group of neurons ( $n=6$; three rats) were tested under conditions 

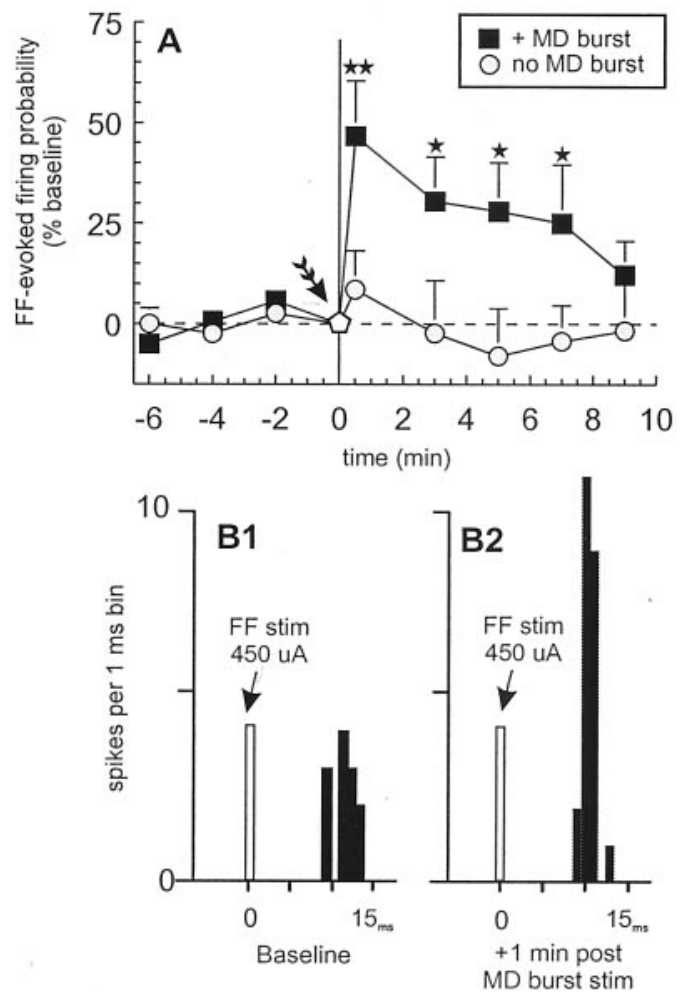

Figure 4. Repeated burst stimulation of the MD potentiates FF-evoked firing in PFC neurons. $A$, In neurons that did not fire in response to MD stimulation, tetanic burst stimulation of the MD (25 4-pulse $20 \mathrm{~Hz}$ trains; interburst interval of $5 \mathrm{sec}$; arrow) potentiated FF-evoked firing for $\sim 10 \mathrm{~min}$ (black squares). In contrast, repeated single-pulse stimulation of the FF alone had no effect (gray circles). Symbols represent mean percentage change (+SEM) in baseline FFevoked firing. $B$, Peristimulus time histograms showing a typical response from a single PFC neuron at baseline (B1) 2 min before and $1 \mathrm{~min}$ after MD tetanus (B2) (25 sweeps each). In this cell, $M D$ tetanus substantially potentiated FF-evoked firing probability. Arrows represent time points at which single pulses were administered to the FF ( $450 \mu \mathrm{A}$ stimulation intensity for both). ${ }^{*} p<0.05$ and ${ }^{* *} p<0.01$, respectively, versus baseline.

in which the MD was not stimulated. These neurons displayed no significant change in the probability of firing evoked by repetitive single-pulse FF stimulations over a $15 \mathrm{~min}$ period $\left(F_{(7,91)}=0.32\right.$, NS) (Fig. 4A, gray circles). Thus, repetitive bursting activity in this thalamocortical pathway can produce a robust, short-term potentiation of hippocampal-evoked firing of PFC neurons, thereby priming PFC neurons to be more responsive to information conveyed by the hippocampus.

\section{Interactions between hippocampal and VTA inputs to the PFC}

\section{Single-pulse stimulation of the FF}

In a separate group of PFC $\leftarrow$ Hipp neurons, we assessed the effect of burst stimulation of the VTA on FF-evoked firing of PFC neurons. All of the neurons tested $(n=54 ; 51$ rats) fired in response to FF stimulation but showed no monosynaptic response after MD stimulation. These data are presented in Figure 5. In accordance with previous findings (Jay et al., 1995; Gurden et al., 1999), burst stimulation of the VTA produced a drastic inhibition of FF-evoked firing $\left(F_{(1,22)}=80.0, p<0.001\right.$; and Dunnett's, $p<$ 0.01 ) (Fig. 5). This inhibitory effect of VTA stimulation was apparent when the interval between the last pulse in the VTA burst and the single stimulation of the FF was either 10 or $50 \mathrm{msec}$ $\left(F_{(1,22)}=8.7 ; p<0.01\right)$. Others have shown that single-pulse stimulation of the VTA inhibits hippocampal-evoked activity only at intervals of $<25 \mathrm{msec}$ (Jay et al., 1995; Gurden et al.,
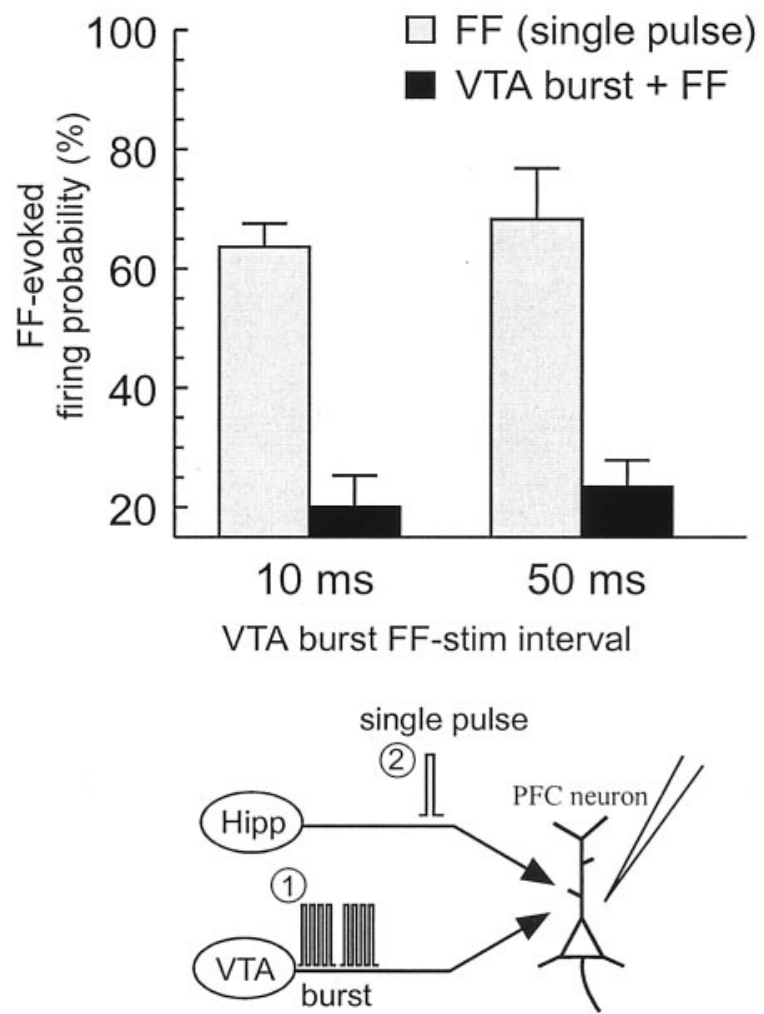

Figure 5. Burst stimulation of the VTA inhibits FF-evoked firing in PFC neurons. Mean firing probability (+SEM) evoked by single-pulse stimulation of the FF alone (gray bars) or after burst stimulation of the VTA (black bars) either 10 or 50 msec before FF stimulation. Bottom panel diagrams stimulation protocol used in this experiment. Here, the VTA was stimulated in a burst pattern (1) (2 4-pulse $20 \mathrm{~Hz}$ trains; interburst interval of $200 \mathrm{msec}$ ) 10 or $50 \mathrm{msec}$ before single-pulse stimulation of the FF (2).

1999). Thus, burst stimulation of the VTA, which is known to be more effective at releasing mesolimbic DA than single pulses (Garris and Wightman, 1994), inhibits firing of PFC neurons evoked by single-pulse stimulation of the hippocampus, and this effect lasts at least $50 \mathrm{msec}$ after the end of the VTA burst.

Train stimulation $(20 \mathrm{~Hz})$ of the FF

A number of recent studies have shown that the actions of DA on evoked activity in PFC neurons are dependent on the frequency at which excitatory inputs are stimulated (Jay et al., 1995; Otani et al., 1998; Gurden et al., 1999; Seamans et al., 2001). In light of these data, we assessed the effect of burst stimulation of the VTA on hippocampal-evoked firing of PFC neurons when the FF was stimulated with a higher-frequency train of pulses. FF stimulation consisted of a five-pulse, $20 \mathrm{~Hz}$ train. Stimulation of the FF in this manner resulted in an equivalent probability of firing (75$90 \%$ ) in PFC neurons throughout each pulse in the train (Figs. $6 \mathrm{~A}$, gray circles, $7 \mathrm{A1}$ ). However, activation of the VTA before 20 $\mathrm{Hz}$ train stimulation of the FF altered this firing profile in an interesting manner. Burst stimulation of the VTA produced a profound reduction in the firing probability observed after the first pulse in the five-pulse train delivered to the FF, when compared with the firing probability observed at the same time point when no VTA stimulation was given (75.8 \pm 4 vs $7.4 \pm 3 \%$ ) (Fig. $6 \mathrm{~A}$, gray square). However, the firing probability observed in the latter parts of the train was significantly less attenuated compared with the firing probability evoked by the first pulse (Figs. 6A, black squares, $7 A 2)\left(\right.$ mean $\left.=52.3 \pm 7 \% ; F_{(4,36)}=7.1 ; p<0.01\right)$. This effect emerged by the second pulse in the train, and the firing 

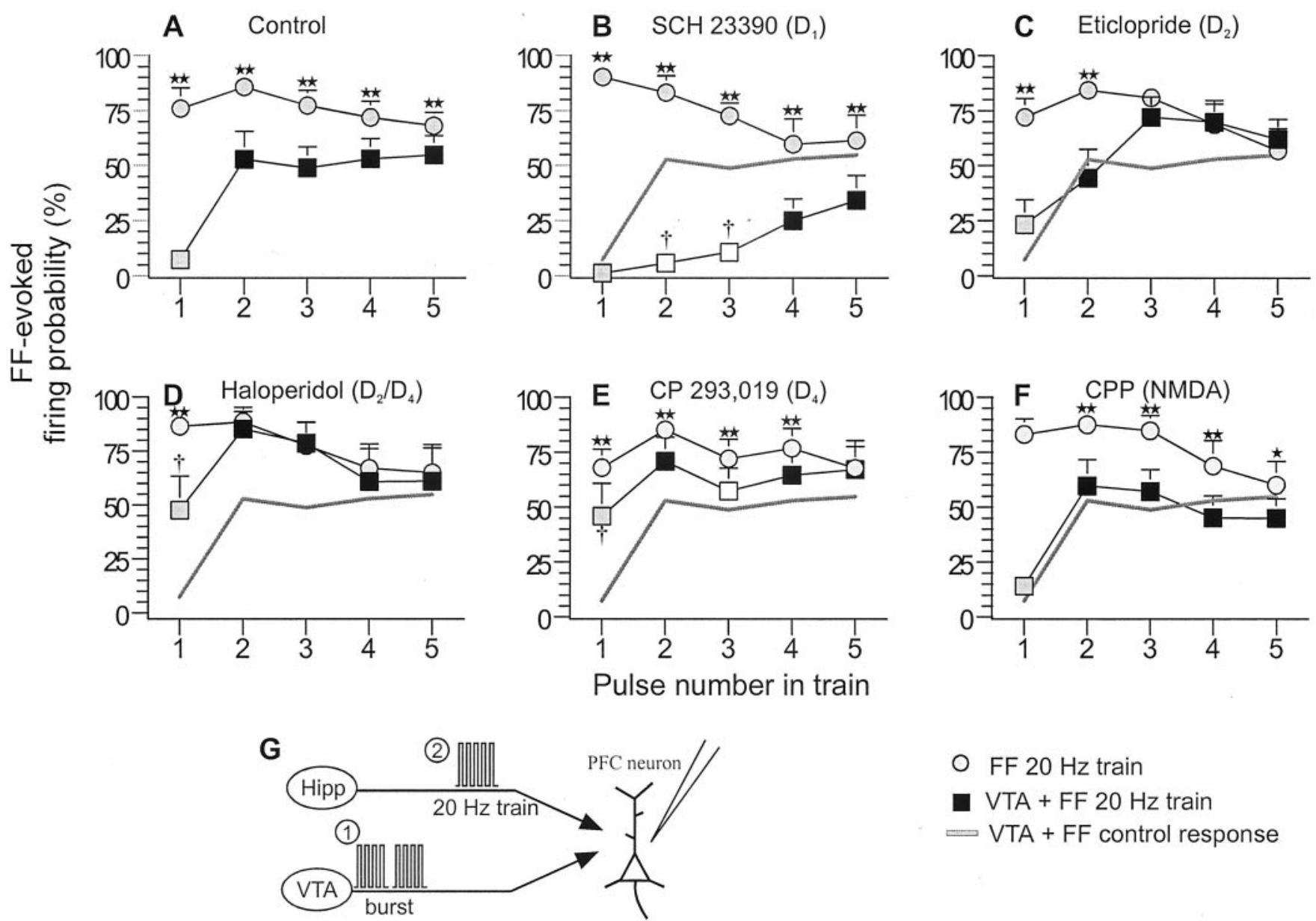

Figure 6. The effects of $D_{1}, D_{2}, D_{4}$, and NMDA receptor blockaded on VTA-induced inhibition of FF-evoked firing in PFC neurons. For all panels, symbols represent mean ( $\left.+S E M\right)$ firing probability evoked by each pulse in a five-pulse train delivered to the FF. Gray circles represent FF-evoked firing probability for each pulse in the five-pulse train, when no VTA stimulation was given. Squares represent FF-evoked firing probability after a VTA burst. Black squares denote significant within-group difference $(p<0.05)$, and white squares denote no significant within-group difference in firing probability observed for latter pulses in the train compared with the firing probability observed during the first pulse (gray square). For comparative purposes, the gray line in $B-F$ represents firing probability of the control condition (VTA + FF). ${ }^{*} p<0.05,{ }^{* *} p<0.01$, significant difference versus probabilities within groups, observed at the same time point in the train with and without VTA stimulation; ${ }^{\dagger} p<0.05$, significant difference in firing probabilities between groups versus those observed at the same time point in the control condition (gray line). $A$, Burst stimulation of the VTA dramatically reduced firing evoked by the first pulse in the train but was less effective for pulses $2-5$. B, Administration of the $D_{1}$ antagonist $S C H 23390$ augmented the VTA-induced inhibition. $C$, The $D_{2}$ antagonist eticlopride abolished the inhibition of firing observed in the latter parts of the train, whereas haloperidol $(D)$ almost completely attenuated the inhibition. The $D_{4}$ antagonist $C P$ 293,019 ( $E$ ) also attenuated the inhibitory effect of VTA stimulation. The NMDA receptor antagonist CPP ( $F$ ) was without effect. $G$, Diagrams of the stimulation protocol used in this experiment. Here, the VTA was stimulated in a burst pattern (1) before five-pulse, $20 \mathrm{~Hz}$ train stimulation of the FF (2).

probability evoked by pulses $2-5$ did not differ throughout the course of the train. It is important to note that burst stimulation of the VTA still caused a significant reduction $(p<0.01)$ in the firing probability evoked by later pulses in the train compared with the firing probability at the same time points of the train when no VTA stimulation was administered, but the magnitude of this inhibition was substantially reduced compared with that observed during the first pulse (first pulse firing probability $=$ $7.4 \pm 3 \%$; pulses $2-5=52.3 \pm 7 \%$; $p<0.01$ ). From these data it is apparent that the inhibitory actions that the VTA exerts over hippocampal-evoked firing in PFC neurons are frequency dependent. Burst stimulation of the VTA can drastically inhibit firing evoked by single-pulse stimulation of the hippocampus. However, if impulse traffic in the hippocampal-PFC pathway occurs in the form of a higher-frequency train of action potentials, the VTA-mediated inhibition is reduced substantially in the latter portions of the train.
Selective DA receptor antagonists alter the effects of VTA stimulation on FF-evoked firing

To ascertain the role that DA receptors play in the effects of VTA stimulation, we administered selective DA receptor antagonists before burst stimulation of the VTA. Analysis of these data revealed significant drug $\times$ pulse number $\times$ VTA stimulation interaction $\left(F_{(20,192)}=1.9 ; p<0.05\right)$. Simple main effects analysis revealed that when no VTA stimulation was administered, there were no significant differences between drug treatment groups with respect to the firing probabilities evoked by train stimulation of the $\operatorname{FF}\left(F_{(5,48)}=0.1 ; \mathrm{NS}\right)$. This finding indicates that any differences between the control condition and the drug treatment group could not be attributed to group differences in the firing probabilities evoked by train stimulation alone. Furthermore, the fact that blockade of $D_{1}, D_{2}$, or $D_{4}$ receptors did not alter firing probabilities evoked by $20 \mathrm{~Hz}$ train stimulation implies that any increase in mesocortical DA release that may be caused by stim- 
ulation of hippocampal afferents (Gurden et al., 2000) does not influence spike firing evoked during train stimulation.

\section{$D_{1}$ receptor blockade}

Administration of the $\mathrm{D}_{1}$ antagonist $\mathrm{SCH}$ 23390 (0.2 mg/kg, i.v.; $n=9)$ markedly enhanced the inhibitory actions of VTA stimulation on firing evoked by train stimulation of the FF (Figs. $6 B, 7 B$ ). Burst stimulation of the VTA caused a pronounced inhibition of firing evoked by the second and third pulse of the five-pulse FF train. In fact, the firing probabilities at these time points did not differ from the firing probability evoked by first pulse (Fig. $6 B$, white squares). Moreover, the firing probability at the middle portion of the train was significantly inhibited compared with the probability observed at the same time points for control neurons. The firing probability evoked by the last two pulses in the train was significantly reduced $(p<$ 0.01 ) when compared with the firing probability at the same time points of the train when no VTA stimulation was administered but was significantly higher $(p<$ 0.01 ) than the firing probability evoked by the first pulse of the train. Thus, $D_{1}$ receptor blockade revealed an underlying potent VTA-mediated inhibition during the latter parts of the train.

\section{$\mathrm{D}_{2}$ receptor blockade}

In contrast to the effects of $\mathrm{D}_{1}$ receptor blockade, intravenous administration of the $D_{2}$ receptor antagonist eticlopride $(0.25$ $\mathrm{mg} / \mathrm{kg} ; n=10$ ) abolished the inhibitory actions of VTA stimulation on firing evoked by the latter parts (pulses 3-5) of train stimulation of the FF but had no significant effect on the inhibition observed during the early parts of the train (Fig. 6C). This attenuation of the VTA-induced inhibition was even more pronounced after pretreatment with the $\mathrm{D}_{2} / \mathrm{D}_{4}$ antagonist haloperi$\mathrm{dol}(0.5 \mathrm{mg} / \mathrm{kg} ; n=8)$. In these cases, VTA stimulation had no effect over the firing probabilities evoked by pulses $2-5$, when compared with the probabilities observed when no VTA stimulation was given (Fig. 6D). Moreover, in the presence of haloperidol, VTA stimulation was less effective at inhibiting firing induced by the first pulse in the train, when compared with the control condition $(p<0.05)$.

\section{$D_{4}$ receptor blockade}

Haloperidol has a higher affinity for $\mathrm{DA}_{4}$ receptors than eticlopride (Durcan et al., 1995; Seeman and Van Tol, 1995; Seeman et al., 1997) and was more effective than eticlopride in attenuating the inhibitory actions of VTA stimulation on FF-evoked activity. In addition, application of $\mathrm{D}_{4}$ antagonists can increase the excitability of PFC neurons (Rubinstein et al., 2001). In keeping with these observations, administration of the selective $\mathrm{DA} \mathrm{D}_{4}$ receptor antagonist CP 293,019 (10 mg/kg; $n=9)$ caused an effect like that of haloperidol but unlike that of eticlopride. $D_{4}$ receptor blockade attenuated significantly $(p<0.05)$ the VTA-induced inhibition of the firing probability evoked by the first pulse of the five-pulse FF train, when compared with neurons in the control condition (Fig. 6E). The effect of CP 293,019 on the firing prob- ability evoked in the latter parts of the train were mixed; $\mathrm{D}_{4}$ receptor blockade appeared to reduce the VTA-induced inhibition of firing evoked by pulses $2-4$, but the firing probability at these time points was still significantly lower when compared with the probabilities observed when no VTA stimulation was given. VTA stimulation did not affect the firing probability evoked by the fifth pulse in the train when compared with the same time point when no VTA stimulation was administered.

\section{NMDA receptor blockade}

Previous studies in vitro have shown that the facilitatory effects of $\mathrm{D}_{1}$ receptor activity on synaptic transmission in the PFC may be co-mediated by the NMDA receptor (Seamans et al., 2001). Therefore, we conducted an experiment to assess whether the frequency-dependent effects observed in the present study were mediated by NMDA receptors. Surprisingly, in eight cells tested, administration of the NMDA receptor antagonist CPP $(2 \mathrm{mg} / \mathrm{kg})$ caused no change in the firing probability evoked by train stimulation of the hippocampus after VTA stimulation (Fig. 6 F). As observed in the control condition, burst stimulation of the VTA drastically reduced the firing probability evoked by the first pulse in the train, whereas firing probability evoked by latter pulses in the train was significantly higher when compared with the first pulse. The discrepancy between the present in vivo study and the effects reported by Seamans et al. (2001) in vitro may be attributed to a number of procedural differences, such as blockade of $\mathrm{Na}^{+}$channels in the study by Seamans and colleagues, the duration of the train used ( 5 vs 15 pulses), the dependent variable (spike firing vs subthreshold EPSPs), and method of DA receptor activation (VTA stimulation vs bath application of a selective $D_{1}$ receptor agonist).

The protocol used in the pharmacological experiments used between-subjects comparisons between animals that received in- 


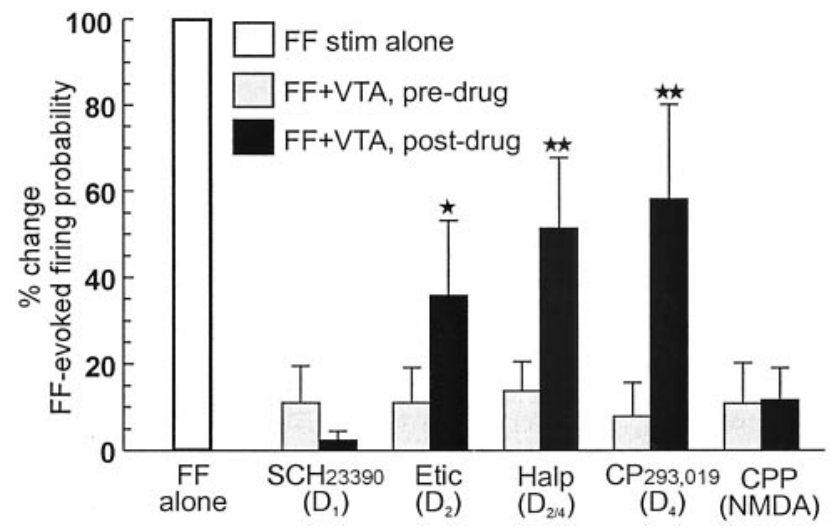

Figure 8. $\quad D_{2}$ and $D_{4}$ but not $D_{1}$ receptor blockade attenuates VTA-mediated inhibition of firing evoked by single-pulse stimulation of the FF. Bars represent the percentage change in firing probability in response to single pulses to the FF after burst stimulation of the VTA before drug administration (gray bar) and 10-20 min after drug administration (black bars). These values are expressed as a percentage change relative to the evoked-firing probability observed when the FF was stimulated alone (open bar; for comparative purposes). Thus, a score of $0 \%$ indicates that no spike firing is elicited by FF stimulation after VTA stimulation, whereas FF stimulation alone is always $100 \%$. Only the $D_{2}$ antagonist eticlopride, the $D_{2} / D_{4}$ antagonist haloperidol, and the $D_{4}$ antagonist CP 293,019 were effective in attenuating the VTA-induced inhibition, whereas the $\mathrm{D}_{1}$ antagonist $\mathrm{SCH} 23390$ and the NMDA antagonist CPP were without effect. Significance at ${ }^{*} p<0.05,{ }^{* *} p<0.01$ versus pre-drug condition.

jections of DA antagonists and those that received no drug treatment. However, as noted above, the effects of VTA stimulation on firing evoked by single-pulse stimulation of the FF was assessed for each individual cell, before any drug administration. Thus, we were able to conduct a within-subjects analysis of the effects of DA receptor blockade on the VTA-induced inhibition of firing evoked by single-pulse stimulation of the FF. Analysis of these data revealed that before drug administration, burst stimulation of the VTA drastically inhibited FF-evoked firing of all neurons in all groups [ $>80 \%$ reduction in firing probability (Fig. 8 , gray bars) when compared with single-pulse stimulation alone (Fig. 8, white bar)]. Similar to the effects observed with train stimulation of the FF, the VTA-induced inhibition of firing evoked by single-pulse stimulation of the FF was not affected by SCH 23390 and was significantly (but not completely) attenuated by eticlopride, haloperidol, and CP 293,019 $\left(F_{(4,32)}=3.0, p<\right.$ 0.05 ; and Dunnett's, $p<0.05, p<0.01$ ) (Fig. 8, black bars). Thus, the finding that blockers for $\mathrm{D}_{2}$ and $\mathrm{D}_{4}$ receptors reduced the effects of burst stimulation of the VTA suggests that the inhibitory actions of VTA stimulation on evoked firing of PFC $\leftarrow$ Hipp neurons is mediated at least in part by the mesocortical DA projection.

To summarize, activation of the VTA exerts a frequencydependent inhibition over firing driven by hippocampal inputs to the PFC. VTA stimulation potently inhibits hippocampalevoked firing evoked by single-pulse stimulation. However, when this pathway is activated at a higher frequency, the inhibition of hippocampal-evoked firing is attenuated, and inputs from the temporal lobe are much more likely to evoke spike firing. The inhibitory actions of the VTA were reduced after blockade of DA $\mathrm{D}_{2}$ and $\mathrm{D}_{4}$ receptors. Moreover, the DA-mediated inhibition induced by stimulation of the VTA appears to have both an early and a late component. Inhibition that occurs $<100 \mathrm{msec}$ after the end of a VTA burst is reduced by $\mathrm{D}_{4}$ receptor blockade (CP 293,019) (Fig. 6E), whereas a later onset inhibition (100-250 msec after a VTA burst) appears to be mediated more prominently by $\mathrm{D}_{2}$ receptors (eticlopride) (Fig. 6C). Accordingly, treat- ment with an antagonist that has affinity for both $\mathrm{D}_{2}$ and $\mathrm{D}_{4}$ receptors (haloperidol) (Fig. 6D) almost completely abolished the inhibitory actions of VTA stimulation. The finding that antagonists for both $\mathrm{D}_{2}$ and $\mathrm{D}_{4}$ receptors did alleviate much of the inhibitory actions of VTA stimulation implies that these effects are mediated primarily by DA and not the mesocortical GABA projection (Carr and Sesack, 2000). Last, blockade of $D_{1}$ receptors disrupted the frequency-dependent modulation of impulse activity in this pathway, augmenting the VTA-mediated inhibition of FF-evoked firing.

\section{Interactions among hippocampal, MD, and VTA inputs to the PFC}

The above-mentioned findings indicate that bursting activity of the VTA can exert a frequency-dependent gating action over PFC neuron firing driven by inputs from the hippocampus. In light of these data, we were interested in assessing what role the VTA may play in modulating the interactions between MD and hippocampal inputs to the PFC. In nine PFC $\leftarrow$ Hipp neurons (nine rats) that also displayed a monosynaptic action potential in response to MD stimulation, we assessed how burst stimulation of the VTA modulated MD gating exerted over hippocampal-evoked firing, using our sequential-pulse stimulation protocol. For these experiments, we only used interpulse intervals of 10-50 msec, because we did not observe any significant effect of MD conditioning pulses applied $>100 \mathrm{msec}$ before FF test pulses, and the magnitude of inhibition of firing by MD conditioning pulses was equivalent at intervals of $25-100 \mathrm{msec}$.

Analysis of these data revealed a significant MD pulse $\times$ VTA stimulation interaction $\left(F_{(2,16)}=5.8 ; p<0.05\right)$ (Fig. 9A). In these cells, the baseline firing probability evoked by MD stimulation and FF stimulation did not differ (FF mean $=59.5 \pm 4 \%$; $\mathrm{MD}$ mean $=63.9 \pm 6 \% ; F_{(1,8)}=0.7 ; \mathrm{NS}$ ). As observed previously (Fig. 2 ), delivery of a conditioning pulse to the MD 10 or $50 \mathrm{msec}$ before stimulation of the FF significantly inhibited FF-evoked firing, when compared with firing evoked by single-pulse stimulation of the FF alone. The inhibition of FF-evoked firing by a conditioning pulse to the MD was significantly greater $(p<0.05)$ when the interval between pulses was 50 versus $10 \mathrm{msec}$ (Fig. $9 A$ ). Burst stimulation of the VTA 10 msec before single-pulse stimulation of the FF also inhibited FF-evoked spike firing $(p<0.05)$. However, application of a conditioning pulse to the MD $10 \mathrm{msec}$ after VTA stimulation, and 10 msec before FF stimulation (i.e., a VTA burst-MD pulse-FF pulse sequence), attenuated the VTAmediated inhibition of FF-evoked firing. The hippocampalevoked firing probability was significantly higher $(p<0.05)$ when compared with firing probability observed after VTA burst-FF stimulation alone. Moreover, at the $10 \mathrm{msec}$ interval between MD and FF stimulation, there was no difference in the firing probabilities observed after a VTA-MD-FF sequence when compared with an MD-FF paired-pulse sequence. This effect was not observed when a longer, $50 \mathrm{msec}$ interval between the MD conditioning pulse and FF test pulse was used. In this instance, a conditioning pulse to the MD $10 \mathrm{msec}$ after VTA stimulation and 50 msec before FF stimulation caused no significant change in the FF-evoked firing probability, when compared with the reduced firing probability displayed after VTA stimulation alone. Thus, as observed previously, activation of either VTA or MD inputs to the PFC can inhibit evoked firing in PFC $\leftarrow$ Hipp neurons. However, during periods of VTA bursting activity, activation of PFC neurons by the MD that occurs nearly simultaneously with activation by hippocampal inputs converging on the same neuron 

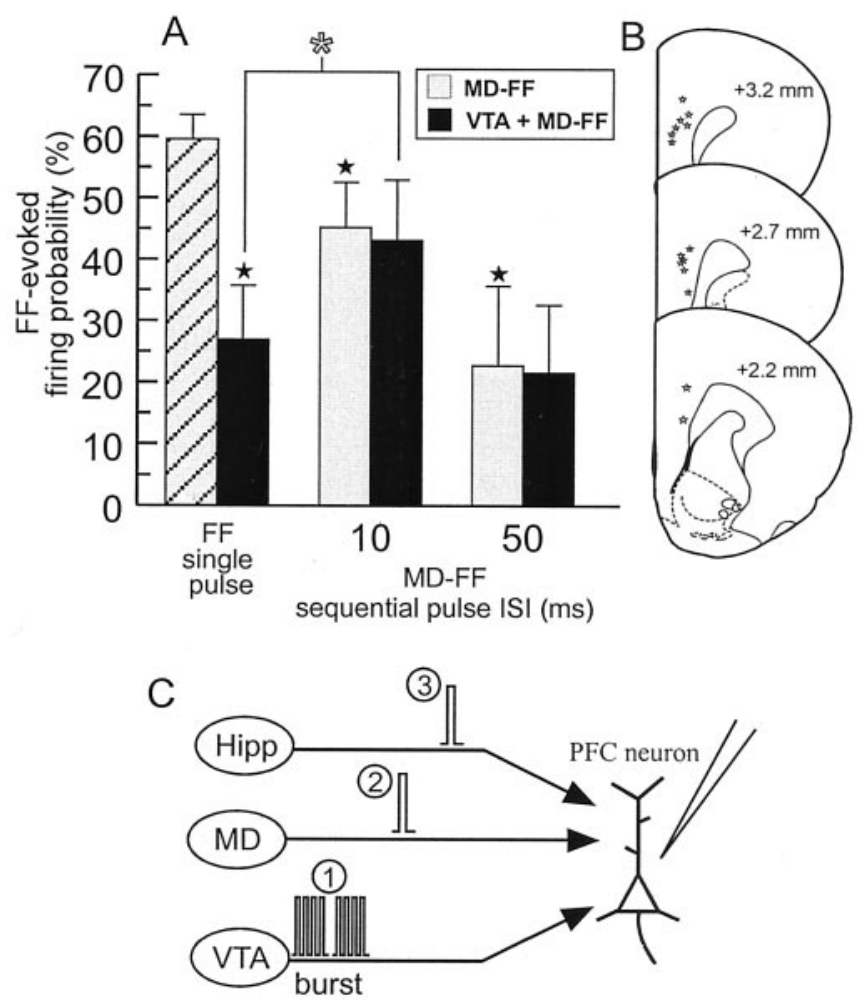

Figure 9. Interactions among hippocampal, MD, and VTA inputs converging on the same PFC neurons. A, FF-evoked firing probabilities in PFC « Hipp neurons that also responded with an orthodromic monosynaptic action potential after stimulation of the MD. Application of a conditioning pulse to the MD 10 or 50 msec before a test pulse to the MD (gray bars) significantly reduced the evoked firing probability relative to that observed when the FF was stimulated alone (gray hatched bar). Burst stimulation of the VTA also attenuated FF-evoked firing (black bars). However, application of a conditioning pulse to the MD 10 msec before an FF test pulse significantly $\left({ }^{*} p<0.05\right)$ attenuated the VTA-mediated inhibition. Stars denote significant difference versus firing probability evoked by FF single-pulse stimulation. B, Location of all neurons observed in this study (open stars) that responded with an orthodromic, monosynaptic action potential after stimulation of the FF and the MD. Numbers beside each plate correspond to millimeters from bregma. C, Diagram of the stimulation protocol used in this experiment. Here the VTA was stimulated in a burst pattern (1) $10 \mathrm{msec}$ before administering MD-FF sequential-pulse stimulation $(2,3)$. Both the MD and FF were stimulated with single pulses that were separated by 10 or $50 \mathrm{msec}$.

can reduce the inhibitory actions that the VTA exerts over spike firing driven by the hippocampus.

\section{Discussion}

Using different stimulation protocols, we report four primary observations: (1) in the majority of PFC $\leftarrow$ Hipp neurons tested, inputs from the MD exert a powerful inhibitory gating action over hippocampal-evoked firing; (2) repetitive burst stimulation of the MD potentiates hippocampal-evoked activity that lasts several minutes; (3) stimulation of the VTA inhibits hippocampal-evoked firing with a preferential attenuation of low-frequency inputs, an effect that was altered after selective blockade of DA receptors. $D_{1}$ receptors facilitate higherfrequency transmission in the hippocampal-PFC pathway, whereas $\mathrm{D}_{2}$ and $\mathrm{D}_{4}$ receptors inhibit firing, and (4) the relative timing of inputs from the MD or VTA determines their impact on PFC neuron responses to hippocampal inputs. Activation of the $\mathrm{MD} \sim 10$ msec before activation of hippocampal inputs was less likely to inhibit hippocampal-evoked firing than at longer intervals. This last finding suggests that inputs from the MD may play a role in heterosynaptic coincidence detection (Usrey, 2002), in- hibiting inputs from the temporal lobe unless they arrive synchronously with diencephalic inputs.

\section{Modulation of the hippocampal-PFC pathway by the MD}

Thalamocortical inputs from the MD typically exerted a pronounced inhibition of hippocampal-evoked firing in PFC neurons. Although there is only preliminary ultrastructural evidence that inputs from the MD synapse on PFC GABAergic interneurons (Kuroda et al., 1998), such an arrangement is commonly reported in other thalamocortical projection systems (Freund et al., 1985; Staiger et al., 1996), and activation of thalamocortical axons yields a threefold larger amplitude EPSP on fast-spiking interneurons as compared with pyramidal neurons (Beierlein and Connors, 2002). Furthermore, stimulation of the MD produces an EPSP-IPSP sequence in PFC neurons (Gigg et al., 1994; Lewis and O'Donnell, 2000), and chemical stimulation of the MD activates $c$-fos immunoreactivity in PFC GABA-containing neurons (Bubser et al., 1998). In the present study, the inhibition of hippocampal-evoked firing after activation of glutamatergic MD afferents is likely mediated by feedforward inhibitory circuits. The fact that this effect was observed in the majority of $\mathrm{PFC} \leftarrow$ Hipp neurons suggests that a large proportion of information that arrives from the hippocampus is under the modulatory control of the MD.

For PFC $\leftarrow$ Hipp neurons that did not fire in response to MD stimulation, activation of thalamocortical afferents with a train of stimuli (but not single pulses) attenuated hippocampal-evoked firing in a majority of neurons. This finding suggests that although relatively few $\mathrm{PFC} \leftarrow$ Hipp neurons appeared to receive direct monosynaptic input from the $\mathrm{MD}$, a larger proportion of these cells can still be modulated by MD inputs in a frequencydependent manner. Reyes et al. (1998) reported that activity of neocortical GABAergic interneurons was facilitated when excitatory inputs were stimulated with a $10 \mathrm{~Hz}$ train. Thus, an increase in activity of MD inputs to the PFC in the $10-40 \mathrm{~Hz}$ range can filter a large ensemble of $\mathrm{PFC} \leftarrow$ Hipp neurons, attenuating firing driven by temporal lobe inputs. This finding parallels phenomena observed in other thalamocortical systems, whereby thalamic nuclei can gate the flow of sensory inputs to the neocortex, producing widespread suppression of activity, thereby focusing cortical sensory representations (Castro-Alamancos, 2002; CastroAlamancos and Oldford, 2002).

In contrast to the above-mentioned effects, $33 \%$ of the PFC $\leftarrow$ Hipp neurons displayed a facilitation of hippocampalevoked firing after train stimulation of the MD, although MD stimulation alone did not evoke firing. Moreover, repeated trains of thalamic stimulation facilitated hippocampal-evoked firing for minutes after tetanus. These data, combined with those described above, suggests the presence of two distinct populations of PFC $\leftarrow$ Hipp neurons: one receives a predominantly inhibitory (presumably polysynaptic) input from the MD, and a second receives a weak excitatory input that by itself is insufficient to evoke spike firing. With respect to this latter population, intracellular recordings have shown that train stimulation of thalamic nuclei can produce an "augmenting response" in sensorimotor cortex, causing a sustained depolarization lasting hundreds of milliseconds (Castro-Alamancos and Connors, 1996; Steriade et al., 1998). This phenomenon is thought to originate in deep cortical layers and activates reverberatory circuits via intralaminar and horizontal collaterals. A similar mechanism may explain the effects observed here: high-frequency activation of subthreshold inputs to the MD would have depolarized a subpopulation proportion of PFC neurons (distinct from those that are inhibited by 
MD activation) and made them more responsive to hippocampal input.

\section{VTA modulation of hippocampal-evoked firing of PFC neurons}

Burst stimulation of the VTA induced a frequency-dependent inhibition over evoked firing in PFC $\leftarrow$ Hipp neurons; these effects were altered by systemic administration of DA antagonists. This observation complements previous findings in which activation of DA receptors promotes a frequency-dependent inhibition over synaptically evoked activity of PFC neurons (Jay et al., 1995; Gurden et al., 1999; Seamans et al., 2001). The faster-onset $(>100 \mathrm{msec}) \mathrm{D}_{4}$-mediated inhibition and a longer-lasting $\mathrm{D}_{2}$ mediated attenuation of spike firing $(\sim 300 \mathrm{msec})$ after a VTA burst may be related to the location of these receptors in the PFC. In addition to being localized on some pyramidal neurons, $\mathrm{D}_{2}$ like receptors in the PFC also reside on GABAergic interneurons (Mrzijak et al., 1996; Wedzony et al., 2001) and on excitatory presynaptic terminals (Sesack et al., 1995). Thus, multiple cellular mechanisms exist by which $\mathrm{D}_{2}$ and $\mathrm{D}_{4}$ receptors could decrease the responsivity of PFC neurons to hippocampal inputs, including facilitation of GABA release (Retaux et al., 1991; Grobin and Deutch, 1998; Zhou and Hablitz, 1999), modulation of the resting membrane potential (Gulledge and Jaffe, 1998, Yang et al., 1999), and presynaptic inhibition of hippocampal inputs. Indeed, in the nucleus accumbens, application of $\mathrm{D}_{2}$ agonists altered hippocampal terminal excitability, implying that DA inhibits hippocampal inputs presynaptically (Yang and Mogenson, 1986). We observed a dramatic alteration in the paired-pulse ratio of FF-evoked firing after VTA stimulation (Fig. 6A), suggesting that mesocortical DA can also inhibit hippocampal inputs presynaptically.

Blockade of $D_{1}$ receptors augmented the VTA-mediated inhibition of hippocampal-evoked firing, abolishing the frequencydependent inhibition that was observed under control conditions. This finding implies that $\mathrm{D}_{1}$ receptor activity can offset the inhibitory actions of $\mathrm{D}_{2}$-like receptors on PFC neuron firing, thereby augmenting the probability that higher-frequency inputs will evoke spiking. These effects parallel those observed in vitro during which excitatory inputs to PFC neurons were stimulated using $20 \mathrm{~Hz}$ trains (Seamans et al., 2001). Bath application of a $\mathrm{D}_{1}$ receptor agonist reduced the EPSP evoked in early parts of the train but enhanced the EPSP in latter parts of the train. In that study, it was found that the facilitatory effects of $D_{1}$ receptors were co-mediated by NMDA receptors. We did not observe a role for NMDA receptor in the $\mathrm{D}_{1}$ modulation of evoked firing, suggesting that $\mathrm{D}_{1}-\mathrm{NMDA}$ interactions may play a more important role in modulating subthreshold EPSPs (Seamans et al., 2001; Wang and O'Donnell, 2001). Alternatively, $\mathrm{D}_{1}$ receptors could increase the excitability of PFC neurons by facilitating persistent $\mathrm{Na}^{+}$(Yang and Seamans, 1996; Gorelova and Yang, 2000; Lavin and Grace, 2001) or $\mathrm{Ca}^{2+}$ conductances (Hernández-López et al., 1997; Wang and O'Donnell, 2001), which would enhance neuron excitability, facilitate temporal summation of inputs, and increase the probability that subsequent EPSPs evoked by latter parts of a train will evoke spiking.

A similar mechanism may underlie the interactions among MD, hippocampal, and VTA inputs to PFC neurons. VTA activation normally inhibits firing evoked by single pulses to the FF. However, impulses from the MD arriving nearly simultaneously with those from the hippocampus may depolarize the neuron, activating intrinsic currents that are susceptible to $D_{1}$ receptor modulation (Lavin and Grace, 2001), which in turn would make the cell more responsive to hippocampal inputs. Collectively, these data suggest that during periods of increased VTA neuron bursting, impulse activity from the hippocampus that arrives either at a higher frequency or in close temporal proximity to impulses from the $\mathrm{MD}$ can be augmented by $\mathrm{D}_{1}$ receptor activity and are less likely to be inhibited by $\mathrm{D}_{2}$-like receptors. As such, inputs from the VTA may be viewed as a "high-pass filter," permitting higher-frequency inputs that exert a stronger depolarizing action and greater control over spike firing of PFC neurons.

\section{Functional implications}

Mnemonic processes mediated by the hippocampal-PFC circuits, such as working memory, are dependent on functional interactions between MD and mesocortical DA input (Gabriel, 1993; Freeman et al., 1996; Floresco et al., 1997, 1999). Similarly, inputs from both the MD and the mesocortical DA system have been implicated in other executive functions mediated by the PFC, such as behavioral flexibility (Hunt and Aggleton, 1998; Ragozzino et al., 1999; Ragozzino, 2002). The present data provide important insights regarding the cellular mechanisms that underlie cognitive processes subserved by neural networks incorporating the frontal and temporal lobes and thalamic and midbrain nuclei. For example, during periods in which reward is anticipated, increased bursting of VTA DA neurons (Schultz, 1998) should limit the flow of information from the hippocampus to the PFC, permitting only the most salient information, arriving in the form of higher-frequency trains of impulses, to evoke firing. Blockade of $\mathrm{D}_{1}$ receptors in the PFC would be expected to attenuate mnemonic-related activity in PFC $\leftarrow$ Hipp neurons and impair working memory (Seamans et al., 1998). In addition, MD neurons also show increased delay-period activity during a delayed response task (Oyoshi et al., 1996). Our data suggest that a prolonged increase in MD activity may facilitate working memory processes, augmenting the excitability of PFC neurons and making them more responsive to information arriving from the hippocampus after a delay. On the other hand, the ability of both the MD and VTA DA inputs to facilitate or inhibit the activity of PFC $\leftarrow$ Hipp neurons may be viewed as a cellular component that permits strategy switching, facilitating the learning of a new behavioral strategy while at the same time inhibiting a previously learned response. Collectively, these data suggest that inputs from the MD and VTA that modulate the activity of PFC $\leftarrow$ Hipp neurons are essential components of cortical-subcortical networks that regulate information processing by the frontal lobes. Disruption in these components would be expected to result in disorganized information processing, behavioral inflexibility, and deficits in working memory. Interestingly, each of these symptoms are observed in schizophrenia, the pathophysiology of which is characterized by dysfunction in both the MD and hippocampal-PFC circuits, as well as a decrease in PFC $\mathrm{D}_{1}$ receptor activity (Weinberger et al., 1994; Okubo et al., 1997; Akil et al., 1999; Friedman et al., 1999; Shenton et al., 2001). The present data suggest that decreased $D_{1}$ receptor activity combined with a hyperexcitable mesolimbic DA system would reduce the transfer of information between the temporal and frontal lobes. Our finding that antipsychotic agents, acting on $\mathrm{D}_{2}$-like receptors, can alleviate the VTA-mediated inhibition of $\mathrm{PFC} \leftarrow$ Hipp neurons suggests that their efficacy in treating psychosis may be attributable in part to their ability to normalize neural activity in these circuits that has been perturbed by alterations in $D_{1}$ receptor activity. 


\section{References}

Akil M, Pierri JN, Whitehead RE, Edgar CL, Mohila C, Sampson AR, Lewis DA (1999) Lamina-specific alterations in the dopamine innervation of the prefrontal cortex in schizophrenic subjects. Am J Psychiatry 156:1580-1589.

Aujla H, Beninger RJ (2001) Hippocampal-prefrontocortical circuits: PKA inhibition in the prefrontal cortex impairs delayed nonmatching in the radial maze in rats. Behav Neurosci 115:1204-1211.

Beierlein M, Connors BW (2002) Short-term dynamics of thalamocortical and intracortical synapses onto layer 6 neurons in neocortex. J Neurophysiol 4:1924-1932.

Bubser M, De Brabander JM, Timmerman W, Feenstra MGP, ErdtsieckErnste EB, Rinnens A, Van Uum JFM, Westerink BHC (1998) Disinhibition of the mediodorsal thalamus induces Fos-like immunoreactivity in both pyramidal and GABA-containing neurons in the medial prefrontal cortex of rats, but does not affect prefrontal levels of GABA. Synapses 30:156-165.

Burette F, Jay TM, Laroche S (1997) Reversal of LTP in the hippocampal afferent fibre system to the prefrontal cortex in vivo with low-frequency patterns of stimulation that do not produce LTD. J Neurophysiol 78:1155-1160.

Carr DB, Sesack SR (1996) Hippocampal afferents to the rat prefrontal cortex: synaptic targets and relation to dopamine terminals. J Comp Neurol 369:1-15.

Carr DB, Sesack SR (2000) Projections from the rat prefrontal cortex to the ventral tegmental area: target specificity in the synaptic associations with mesoaccumbens and mesocortical neurons. J Neurosci 19:3723-3730.

Castro-Alamancos MA (2002) Role of thalamocortical sensory suppression during arousal: focusing sensory inputs in neocortex. J Neurosci 22:96519655.

Castro-Alamancos MA, Connors BW (1996) Cellular mechanisms of the augmenting response: short term plasticity in a thalamocortical pathway. J Neurosci 16:7742-7756.

Castro-Alamancos MA, Oldford E (2002) Cortical sensory suppression during arousal is due to the activity-dependent depression of thalamocortical synapses. J Physiol (Lond) 541:319-331.

Conde F, Maire-Lepoivre E, Audinat E, Crepel F (1995) Afferent connections of the medial frontal cortex of the rat. II. Cortical and subcortical afferents. J Comp Neurol 325:567-593.

Daum I, Ackermann H (1994) Frontal-type memory impairment with thalamic damage. Int J Neurosci 77:187-198.

Durcan MJ, Rigdon GC, Norman MH, Morgan PF (1995) Is clozapine selective for the dopamine D4 receptor? Life Sci 57:275-283.

Floresco SB, Seamans JK, Phillips AG (1997) Selective roles for hippocampal prefrontal cortical, and ventral striatal circuits in radial-arm maze tasks with or without a delay. J Neurosci 17:1880-1890.

Floresco SB, Braaksma DN, Phillips AG (1999) Thalamic-cortical-striatal circuitries mediate working memory during delayed responding on a radial-arm maze. J Neurosci 19:11061-11071.

Floresco SB, Blaha CD, Yang CR, Phillips AG (2001) Modulation of hippocampal and amygdalar-evoked activity of nucleus accumbens neurons by dopamine: cellular mechanisms of input selection. J Neurosci 21:28512860.

Freeman JH, Cuppernell C, Flannery K, Gabriel M (1996) Context-specific multi-site cingulate cortical, limbic thalamic, and hippocampal neuronal activity during concurrent discriminative approach and avoidance training in rabbits. J Neurosci 16:1538-1549.

Freund TF, Martin KA, Somogyi P, Whitteridge D (1985) Innervation of cat visual areas 17 and 18 by physiologically identified $\mathrm{X}$ and Y-type afferents II: identification of postsynaptic targets by GABA immunochemistry and Golgi impregnation. J Comp Neurol 242:275-291.

Friedman JI, Temporini H, Davis KL (1999) Pharmacologic strategies for augmenting cognitive performance in schizophrenia. Biol Psychiatry 45:1-16.

Fuster JM (2001) The prefrontal cortex —an update: time is of the essence. Neuron 30:319-333.

Gabbott P, Headlam A, Bubsy S (2002) Morphological evidence that CA1 hippocampal afferents monosynaptically innervate PV-containing neurons and NADPH-diaphorase reactive cells in the medial prefrontal cortex (areas 25/32) of the rat. Brain Res 946:314-322.

Gabriel M (1993) Discriminative avoidance learning: a model system. In: Neurobiology of the cingulate cortex and limbic thalamus: a comprehen- sive handbook (Vogt BA, Gabriel M eds), pp 478-523. Boston, MA Birkhäuser.

Garris PA, Wightman RM (1994) Different kinetics govern dopaminergic transmission in the amygdala, prefrontal cortex, and striatum: an in vivo voltammetric study. J Neurosci 14:442-450.

Gigg J, Tan AM, Finch DM (1994) Glutamatergic hippocampal formation projections to prefrontal cortex in the rat are regulated by GABAergic inhibition and show convergence with glutamatergic projections from limbic thalamus. Hippocampus 4:189-198.

Gioanni Y, Thierry AM, Glowinski J, Tassin JP (1998) Alpha1-adrenergic, $\mathrm{D} 1$, and D2 receptors interactions in the prefrontal cortex: implications for the modality of action of different types of neuroleptics. Synapse 30:362-370.

Goldman-Rakic PS (1998) The prefrontal landscape: implications of functional architecture for understanding human mentation and the central executive. In: The prefrontal cortex: executive and cognitive functions (Roberts AC, Robbins TW, Weizkrantz L, eds), pp 67-86. Oxford: Oxford UP.

Gorelova N, Yang CR (2000) Dopamine D1/D5 receptor activation modulates a persistent sodium current in rat prefrontal cortical neurons in vitro. J Neurophysiol 84:75-87.

Grobin AC, Deutch AY (1998) Dopaminergic regulation of extracellular gamma-aminobutyric acid levels in the prefrontal cortex of the rat. J Pharmacol Exp Ther 285:350-357.

Groenewegen HJ (1988) Organization of the afferent connections of the mediodorsal thalamic nucleus in the rat, related to the mediodorsalprefrontal topography. Neuroscience 24:379-431.

Gulledge AT, Jaffe DB (1998) Dopamine decreases the excitability of layer V pyramidal cells in rat prefrontal cortex. J Neurosci 18:9139-9151.

Gurden H, Tassin J-P, Jay TM (1999) Integrity of the mesocortical dopaminergic system is necessary for complete expression of in vivo hippocampalprefrontal cortex long-term potentiation. Neuroscience 94:1019-1027.

Gurden H, Takita M, Jay TM (2000) Essential role of D1 but not D2 receptors in the NMDA receptor-dependent long-term potentiation at hippocampalprefrontal cortex synapses in vivo. J Neurosci 20:RC106(1-5).

Hampson RE, Hedberg T, Deadwyler SA (2000) Differential information processing by hippocampal and subicular neurons. Ann NY Acad Sci 911:151-165.

Hauser MD (1999) Perseveration, inhibition and the prefrontal cortex: a new look. Curr Opin Neurobiol 9:214-222.

Hernández-López S, Bargas J, Surmeier DJ, Reyes A, Galarraga E (1997) D1 receptor activation enhances evoked discharge in neostriatal medium spiny neurons by modulating an L-type $\mathrm{Ca}^{2+}$ conductance. J Neurosci 17:3334-3342.

Hunt PR, Aggleton JP (1998) Neurotoxic lesions of the dorsomedial thalamus impair the acquisition but not the performance of delayed matching to place by rats: a deficit in shifting response rules. J Neurosci 18:1004510052.

Jay TM, Glowinski J, Thierry AM (1995) Inhibition of hippocampoprefrontal cortex excitatory responses by the mesocortical DA system. NeuroReport 6:1845-1848.

Joyce EM, Robbins TW (1991) Frontal lobe function in Korsakoff and nonKorsakoff alcoholics: planning and spatial working memory. Neuropsychologia 29:709-723.

Kolb B (1984) Functions of the frontal cortex of the rat: a comparative review. Brain Res 320:65-98.

Krettek JE, Price J (1977) The cortical projections of the mediodorsal nucleus and adjacent thalamic nuclei in the rat. J Comp Neurol 171:157-192.

Kuroda M, Yokofujita J, Murakami K (1998) An ultrastructural study of the neural circuit between the prefrontal cortex and the mediodorsal nucleus of the thalamus. Prog Neurobiol 54:417-458.

Lavin A, Grace AA (2001) Stimulation of D1-type dopamine receptors enhances excitability in prefrontal cortical pyramidal neurons in a statedependent manner. Neuroscience 104:335-346.

Lewis BL, O'Donnell P (2000) Ventral tegmental area afferents to the prefrontal cortex maintain membrane potential "up" states in pyramidal neurons via D1 dopamine receptors. Cereb Cortex 10:1168-1175.

Mansbach RS, Brooks EW, Sanner MA, Zorn SH (1998) Selective dopamine D4 receptor antagonists reverse apomorphine-induced blockade of prepulse inhibition. Psychopharmacology 135:194-200.

Miller EK (2000) The prefrontal cortex and cognitive control. Nat Rev Neurosci 1:59-65. 
Mrzijak L, Bergson C, Pappy M, Huff R, Levenson R, Goldman-Rakic PS (1996) Localization of dopamine D4 receptors in GABAergic neurons of the primate brain. Nature 381:245-248.

Mulder AB, Arts MPM, Lopes da Silva FH (1997) Short- and long-term plasticity of the hippocampus to nucleus accumbens and prefrontal cortex pathways in the rat, in vivo. Eur J Neurosci 9:1603-1611.

Mulkey RM, Malenka RC (1992) Mechanisms underlying induction of homosynaptic long-term depression in area CA1 of the hippocampus. Neuron 9:967-975.

Okubo Y, Suhara T, Suzuki K, Kobayashi K, Inoue O, Terasaki O, Someya Y, Sassa T, Sudo Y, Matsushima E, Iyo M, Tateno Y, Toru M (1997) Decreased prefrontal dopamine D1 receptors in schizophrenia revealed by PET. Nature 385:634-636.

Otani S, Blond O, Desce JM, Crepel F (1998) Dopamine facilitates longterm depression of glutamatergic transmission in rat prefrontal cortex. Neuroscience 85:669-676.

Oyoshi T, Nishijo H, Asakura T, Takamura Y, Ono T (1996) Emotional and behavioral correlates of mediodorsal thalamic neurons during associative learning in rats. J Neurosci 16:5812-5829.

Pirot S, Jay TM, Glowinski J, Thierry AM (1994) Anatomical and electrophysiological evidence for an excitatory amino acid pathway from the thalamic mediodorsal nucleus to the prefrontal cortex in the rat. Eur J Neurosci 6:1225-1234.

Ragozzino ME (2002) The effects of dopamine D1 receptor blockade in the prelimbic-infralimbic areas on behavioral flexibility. Learn Mem 9:18-28.

Ragozzino ME, Detrick S, Kesner RP (1999) Involvement of the prelimbicinfralimbic areas of the rodent prefrontal cortex in behavioral flexibility for place and response learning. J Neurosci 19:4585-4594.

Ray JP, Price JL (1992) The organization of the thalamocortical connections of the mediodorsal thalamic nucleus in the rat, related to the ventral forebrain-prefrontal cortex topography. J Comp Neurol 323:167-197.

Retaux S, Besson MJ, Penit-Soria J (1991) Opposing effects of dopamine D2 receptor stimulation on the spontaneous and the electrically evoked release of $\left[{ }^{3} \mathrm{H}\right] \mathrm{GABA}$ on rat prefrontal cortex slices. Neuroscience 42:61-71.

Reyes A, Lujan R, Rozov A, Burnashev N, Somogyi P, Sakmann B (1998) Target-cell-specific facilitation and depression in neocortical circuits. Nat Neurosci 4:279-285.

Robbins TW (1996) Dissociating executive functions of the prefrontal cortex. Philos Trans R Soc Lond B Biol Sci 351:1463-1470.

Rubinstein M, Cepeda C, Hurst RS, Flores-Hernandez J, Ariano MA, Falzone TL, Kozell LB, Meshul CK, Bunzow JR, Low MJ, Levine MS, Grandy DK (2001) Dopamine D4 receptor-deficient mice display cortical hyperexcitability. J Neurosci 21:3756-3763.

Schultz W (1998) Predictive reward signal of dopamine neurons. J Neurophysiol 80:1-27.

Seeman P, Van Tol HH (1995) Deriving the therapeutic concentrations for clozapine and haloperidol: the apparent dissociation constant of a neuroleptic at the dopamine D2 or D4 receptor varies with the affinity of the competing radioligand. Eur J Pharmacol 291:59-66.

Seeman P, Corbett R, Van Tol HH (1997) Atypical neuroleptics have low affinity for dopamine D2 receptors or are selective for D4 receptors. Neuropsychopharmacology 16:93-110.

Seamans JK, Floresco SB, Phillips AG (1998) D1 receptor modulation of hippocampal-prefrontal cortical circuits integrating spatial memory with executive functions in the rat. J Neurosci 18:1613-1621.

Seamans JK, Durstewitz D, Christie B, Stevens CF, Sejnowski TJ (2001) Dopamine D1/D5 receptor modulation of excitatory synaptic inputs to layer V prefrontal cortex neurons. Proc Natl Acad Sci USA 98:301-306.

Sesack SR, Bunney BS (1989) Pharmacological characterization of the receptor mediating electrophysiological responses to dopamine in the rat medial prefrontal cortex: a microiontophoretic study. J Pharmacol Exp Ther 248:1323-1333.

Sesack SR, King SW, Bressler CN, Watson SJ, Lewis DA (1995) Electron microscopic visualization of dopamine D2 receptors in the forebrain: cellular, regional, and species comparisons. Soc Neurosci Abstr 21:365.

Shenton ME, Dickey CC, Frumin M, McCarley RW (2001) A review of MRI findings in schizophrenia. Schizophrenia Res 49:1-52.

Staiger JF, Zilles K, Freund TF (1996) Distribution of GABAergic elements postsynaptic to ventroposteromedial thalamic projections in layer IV of rat barrel cortex. Eur J Neurosci 11:2273-2285.

Steriade M, Timofeev I, Grenier F, Dürmüller N (1998) Role of thalamic and cortical neurons in augmenting responses and self-sustained activity: dual intracellular recordings in vivo. J Neurosci 18:6425-6443.

Usrey WM (2002) The role of spike timing for thalamocortical processing. Curr Opin Neurobiol 12:411-417.

Van Eden CG, Hoorneman EMD, Buijs RM, Mathussen MAH, Geffard M, Uylings HBM (1987) Immunohistochemical localization of dopamine in the prefrontal cortex of the rat at the light, electron microscopal level. Neuroscience 22:849-862.

Wang J, O'Donnell P (2001) D1 dopamine receptors potentiate NMDAmediated excitability increase in layer $\mathrm{V}$ prefrontal cortical pyramidal neurons. Cereb Cortex 11:452-462.

Wedzony K, Chocyk A, Mackowiak M, Fijal K, Czyrak A (2001) Cortical localization of dopamine D4 receptors in the rat brain-immunocytochemical study. J Physiol Pharmacol 51:205-221.

Weinberger DR, Aloia MS, Goldberg TE, Berman KF (1994) The frontal lobes and schizophrenia. J Neuropsychiatry Clin Neurosci 6:419-427.

Yang CR, Mogenson GJ (1986) Dopamine enhances terminal excitability of hippocampal-accumbens neurons via D2 receptor: role of dopamine in presynaptic inhibition. J Neurosci 6:2470-2478.

Yang CR, Seamans JK (1996) Dopamine D1 receptor actions in layers V-VI rat prefrontal cortex neurons in vitro: modulation of dendritic-somatic signal integration. J Neurosci 16:1922-1935.

Yang CR, Seamans JK, Gorelova N (1999) Developing a neuronal model for the pathophysiology of schizophrenia based on the nature of electrophysiological actions of dopamine in the prefrontal cortex. Neuropsychopharmacology 21:161-194.

Zhou F-M, Hablitz JJ (1999) Dopamine modulation of membrane and synaptic properties of interneurons in rat cerebral cortex. J Neurophysiol 81:967-976. 